Reference: Biol. Bull. 232: 45-57. (February 2017)

(C) 2017 The University of Chicago

\title{
Protection from Oxidative Stress in Immunocytes of the Colonial Ascidian Botryllus schlosseri: Transcript Characterization and Expression Studies
}

\author{
NICOLA FRANCHI, FRANCESCA BALLIN*, AND LORIANO BALLARIN \\ Department of Biology, University of Padova,Via Ugo Bassi 58/B, 35121 Padova, Italy
}

\begin{abstract}
Botryllus schlosseri is a cosmopolitan colonial ascidian that undergoes cyclical generation changes, or takeovers, during which adult zooids are resorbed and replaced by their buds. At take-over, adult tissues undergo diffuse apoptosis and effete cells are massively ingested by circulating phagocytes, with a consequent increase in oxygen consumption and in production of reactive oxygen species (ROS). The latter are responsible for the death of phagocytes involved in the clearance of apoptotic cells and corpses by phagocytosisinduced apoptosis. However, the majority of phagocytes and hemocytes do not die, even if they experience oxidative stress. This fact suggests the presence of detoxification mechanisms assuring their protection. To test this assumption, we searched for transcripts of genes involved in detoxification in the transcriptome of $B$. schlosseri. We identified and characterized transcripts for $\mathrm{Cu} / \mathrm{Zn}$ superoxide dismutase (SOD), $\gamma$ glutamyl-cysteine ligase modulatory subunit (GCLM), gluta-
\end{abstract}

Received 25 July 2016; accepted 30 January 2017; Published online 3 April 2017.

*To whom correspondence should be received. E-mail: ballin.fra@ gmail .com

Abbreviations: AG, adenine guanine (splicing consensus signal); ATG, start signal; CDS, coding sequences; $\mathrm{Cu} / \mathrm{Zn} \mathrm{SOD}, \mathrm{Cu}-\mathrm{Zn}$ superoxide dismutase; EST, expressed sequence tag; GCL, $\gamma$-glutamyl-cysteine ligase; GCLC, catalytic subunit of $\gamma$-glutamyl-cysteine ligase; GCLM, modulatory subunit of $\gamma$-glutamyl-cysteine ligase; GPx, glutathione peroxidase; GS, glutathione synthase; GSH, glutathione; GSSG, oxidized glutathione; GT, guanine timine (splicing consensus signal); ISH, in situ hybridization; MC, mid-cycle; ME, minimum evolution; ML, maximum likelihood; MP, maximum parsimony; $\mathrm{NADPH}$, nicotinamide adenine dinucleotide phosphate; NJ, neighbor-joining; PBS, phosphate-buffered saline; PCR, polymerase chain reaction; PO, phenoloxidase; RACE, rapid amplification of the cDNA ends; ROS: reactive oxygen species; SEC, selenocysteine; SECIS, selenocysteine insertion sequence; SOD, superoxide dismutase; SODb, type B SOD; TAG, stop codon; TGA, thymine, guanine, and adenine nucleotides (stop codon); TO, take-over; UPGMA, unweighted pair group with arithmetic mean; UTR, untranslated region. thione synthase (GS), and two glutathione peroxidases (i.e., GPx3 and GPx5), all involved in protection from ROS. We also carried out a phylogenetic analysis of the putative amino acid sequences, confirming their similarity to their vertebrate counterparts, and studied the location of their mRNAs by in situ hybridization on hemocyte monolayers. We also analyzed gene transcription during the colonial blastogenetic cycle, which is the interval of time between one take-over and the next, by qRT-PCR. In addition, we investigated the effects of cadmium $(\mathrm{Cd})$, an inducer of oxidative stress, on gene transcription. Our results indicated that i) antioxidant gene expression is modulated in the course of the blastogenetic cycle and upon exposure to $\mathrm{Cd}$, and ii) hemocytes synthesize both enzymatic and nonenzymatic antioxidants, in line with the idea that they represent a major detoxification system for ascidians.

\section{Introduction}

Increasing evidence indicates that stressful conditions lead animals to increase the production of reactive oxygen species (ROS) by NADPH-, mitochondrial-, and microsomal-oxidase activity, which partially reduces molecular oxygen (Kaloyanni et al., 2009; Tomanek, 2014; Canesi, 2015; Puppel et al., 2015; Zeeshan et al., 2016). Reactive oxygen species, including superoxide anions $\left(\cdot \mathrm{O}_{2}^{-}\right)$, hydrogen peroxide $\left(\mathrm{H}_{2} \mathrm{O}_{2}\right)$, peroxyl radicals $\left(\cdot \mathrm{RO}_{2}\right)$, and hydroxyl radicals $(\cdot \mathrm{OH})$, exert microbicidal activity and prevent potentially pathogenic microorganisms from entering the weakened organisms. They can also activate signal transduction pathways mediating cell growth and apoptosis (De la Fuente and Victor, 2000; Lesser, 2006). Even in the immune system, phagocytes, once they are activated by the recognition of foreign molecules, increase their oxygen consumption in a process known as oxidative burst. This involves the activation of an inducible membrane oxidase and the consequent production of ROS. 
When ROS levels exceed a threshold value, an imbalance occurs between the production of ROS and the ability of the cell and/or organism to readily detoxify the reactive intermediates or to repair the resulting damage. This condition, currently known as oxidative stress, is dangerous for cells and tissues because it can lead to the oxidation of lipids, proteins, and nucleic acids, producing irreversible structural and functional alterations. To prevent the negative effects of ROS, organisms evolved antioxidant defenses that can reestablish the cellular redox equilibrium, relying on both enzymatic and nonenzymatic mechanisms. Enzymes such as superoxide dismutase (SOD), catalase, glutathione reductase, and glutathione peroxidase (GPx) belong to the first category, whereas thiolrich molecules, such as glutathione (GSH), metallothioneins, and phytochelatins, number among the nonenzymatic mechanisms.

Tunicates are invertebrate chordates and are considered the sister group of vertebrates (Delsuc et al., 2006). For this reason, they are interesting organisms for evolutionary studies. Ascidians are the richest in species class of tunicates and thus are the most studied animal of this class.

Botryllus schlosseri is a colonial ascidian that performs cyclical (weekly, at $20^{\circ} \mathrm{C}$ ) generation changes, or take-overs, allowing recurrent rejuvenation of colonies (Manni et al., 2007; Ballarin et al., 2010). Colonies include three blastogenetic generations represented by mature, filter-feeding zooids, primary buds on zooids, and secondary buds (budlets) emerging from the primary buds (Manni et al., 2007). During the generation change, lasting 24-36 h, tissues of adult zooids undergo diffuse apoptosis (Lauzon et al., 1992, 1993; Cima and Ballarin, 2009; Ballarin et al., 2010), and cells and corpses are rapidly ingested by phagocytes infiltrating the tissues after having left the circulation (Cima et al., 2003; Manni et al., 2007; Ballarin et al., 2008a, b). In addition, a fraction of hemocytes, corresponding to $20 \%-30 \%$ of the total circulating cells, die by apoptosis at take-over and are replaced by new, undifferentiated hemocytes that enter the circulation from the hematopoietic sites (Ballarin et al., 2008b). Among these are the phagocytes having ingested effete cells and corpses that tend to die by phagocytosis-induced apoptosis as a consequence of excessive respiratory burst (Cima et al., 2010; Franchi et al., 2016). Reactive oxygen species are also produced when cytotoxic morula cells sense the presence of nonself (Ballarin et al., 2001) and release the enzyme phenoloxidase, which is stored in an inactive form inside their granules (Cima et al., 2004; Franchi et al., 2015). Phenoloxidase, acting on polyphenol substrata that are also released by morula cells, causes the production of ROS with microbicidal activity, for instance, during the nonfusion reaction between in-contact, genetically incompatible colonies (Ballarin et al., 2002; Franchi et al., 2015). Therefore, at take-over, when massive phagocytosis occurs, and during cytotoxic immune responses the majority of hemocytes need to protect themselves from the potential damages induced by ROS.
Until now, ascidian antioxidant strategies have been studied in the solitary species Ciona intestinalis (Franchi et al., 2012, 2014; Ferro et al., 2013) and Halocyntia roretzi (Abe et al., 1999). Available data suggest that circulating hemocytes, in addition to their role in immune responses (Ballarin et al., 2008b), are directly involved in the synthesis of ROSscavenging molecules (Franchi et al., 2012, 2014; Ferro et al., 2013).

In the present study, we started a characterization of the ROS detoxification mechanisms in the hemocytes of $B$. schlosseri. New transcripts for Botryllus $\mathrm{Cu} / \mathrm{Zn}$ superoxide dismutase (SOD), $\gamma$-glutamyl-cysteine ligase modulatory subunit (GCLM), glutathione synthase (GS), and two glutathione peroxidases (GPx3 and GPx5) are described, and their location in hemocytes is demonstrated through in situ hybridization (ISH). We also compared the level of mRNA transcription in colonies exposed to $\mathrm{Cd}-\mathrm{a}$ known inducer of oxidative stress (Liu et al., 2009) with respect to untreated coloniesby qRT-PCR. Our results indicated that immunocytes (both phagocytes and cytotoxic morula cells) are active in the transcription of genes involved in ROS detoxification, and their activity is modulated during the blastogenetic cycle and by the presence of $\mathrm{Cd}$.

\section{Materials and Methods}

\section{Animals}

Colonies of Botryllus schlosseri (Tunicata, Ascidiacea) were collected near Chioggia, in the southern part of the Lagoon of Venice. They were reared according to the method of Gasparini et al. (2015), affixed to glass slides $(5 \times 5 \mathrm{~cm})$, in aerated aquaria filled with $0.45-\mu \mathrm{m}$ filtered seawater (FSW) that was changed every other day, held at a constant temperature of $19{ }^{\circ} \mathrm{C}$, and fed with Liquifry marine (Liquifry Co., Dorking, UK). Under these conditions, colonies reproduce asexually by palleal budding and undergo take-over weekly. Within 24-36 h, old zooids are resorbed and replaced by their buds. A colonial blastogenetic cycle is defined as the period of time between one take-over and the next. Colonial developmental phases lasting more than one day from the preceding, or following, generation change are collectively known as midcycle (MC; Manni et al., 2007).

\section{Hemocyte collection}

A colorless hemolymph containing various kinds of circulating hemocytes flows inside the lacunae and sinuses of the zooid open circulatory system and in the tunic vasculature that connects all the zooids and buds of the colony. Most of the circulating hemocytes are immunocytes, represented by phagocytes (both spreading and round) and cytotoxic morula cells (Ballarin and Cima, 2005).

Hemolymph was collected with a glass micropipette after puncture, using a fine tungsten needle, of the tunic marginal 
vessels of the colonies. It was diluted $1: 1$ in $0.38 \% \mathrm{Na}-$ citrate in FSW (as an anti-agglutinating agent) with $\mathrm{pH} 7.5$, then centrifuged at $780 \mathrm{~g}$ for $10 \mathrm{~min}$ at room temperature. The resulting pellet was then resuspended in FSW to get a final concentration of $5 \times 10^{5}$ hemocytes $/ \mathrm{ml}$.

\section{Exposure to cadmium}

A storage solution was prepared by dissolving $\mathrm{CdCl}_{2}$ in distilled water, whose concentration was determined by atomic absorption spectrometry, using a PerkinElmer 4000 spectrometer (PerkinElmer, Watham, MA), resulting in $45 \mathrm{mmol}^{-1}$. It was subsequently diluted in FSW to obtain a working solution with a final concentration of $0.2 \mu \mathrm{mol} 1^{-1}$. This concentration, although higher than those found in the environment, was effective in inducing oxidative stress in the hemocytes of Botryllus schlosseri (Franchi and Ballarin, 2013), and was within the concentration ranges used in toxicological experiments with other aquatic organisms (Jeppe et al., 2014; Koutsogiannaki et al., 2015; Mùgica et al., 2015).

Nine colonies of comparable size (around 25 zooids each) were exposed to $0.2 \mu \mathrm{mol}^{-1} \mathrm{CdCl}_{2}$ in $\mathrm{FSW}$, in $39-1$ aquaria ( 3 colonies per aquarium), at $16{ }^{\circ} \mathrm{C}$. Three additional, unexposed colonies were used as controls. To avoid interference with the ROS production associated with the generation change (Cima et al., 2010), exposed colonies were at the mid-cycle phase of the blastogenetic cycle; exposure time was limited to 2, 4, and $6 \mathrm{~h}$. Previous results indicated that the effects of $\mathrm{Cd}$ exposure on hemocytes were already observable after a one-hour exposure (Franchi and Ballarin, 2013). After the exposure, colonies were collected, blotted dry, removed from the glass slides with a razor blade, frozen in liquid nitrogen, and stored at $-80{ }^{\circ} \mathrm{C}$ until use.

Primer design, RNA extraction, cDNA synthesis, cloning, and sequencing

Our EST collection was aligned on the Botryllus genome already available online (Voskoboynik et al., 2013). With this approach, many coding sequences (CDS) were recognized and recorded in our database (Campagna et al., 2016). Comparison of our CDS collection (Campagna et al., 2016) with the sequences of the vertebrate genes of interest allowed us to identify a series of nucleotide sequences and to design specific primers (Table 1) for PCR amplification. We focused our attention on the sequences of the predicted transcripts for GCLM, GS, Cu/Zn-SOD, GPx3, and GPx5, known as BsGCLM, BsGS, BsCu/Zn-SOD, BsGPx3, and BsGPx5, respectively. In all cases, the obtained EST sequences contained a $5^{\prime}$-terminal untranslated region (UTR) and the entire coding region. The $3^{\prime}$-rapid amplification of the cDNA ends (RACE) was performed using the $5^{\prime} / 3^{\prime}$ RACE Kit $2^{\text {nd }}$ Generation (Roche Molecular Systems, Inc., Pleasanton, CA).
Table 1

$P C R$ primers used and relative melting temperatures (Tm)

\begin{tabular}{lll}
\hline \hline \multicolumn{1}{c}{ Primer } & Tm $\left({ }^{\circ} \mathrm{C}\right)$ & \multicolumn{1}{c}{ Sequence 5'-3' $^{\prime}$} \\
\hline BsGCLF & 53 & GTTGGAAAGAATCGGTAGGG \\
BsGCLFR & 57.4 & GCTTGGAATGACTTCTCAGGGAG \\
BsGCLF-RT & 53.9 & CGAAAGCGTTGAGTGTATGG \\
BsGCLM-RT & 56.9 & CAAAATCAGTCACGCCGATGTG \\
BsGSF & 55.2 & CGAAGCCAACATCATCCGA \\
BsGSR & 55 & CTCGGTTCGCTCTCATCTG \\
BsGSF-RT & 60 & CATGCGATCAGTCAAGATCC \\
BsGSR-RT & 60 & TTGCCATTGCAGTCTTCTTG \\
BsGPx5F & 57.8 & CATTGCTTGTTGCGAGTGCC \\
BsGPx5R & 57 & GCCACCAGAGTGTCCCATA \\
BsGPx5F-RT & 60 & GGAAATGGATGGACGCCGCA \\
BsGPx5R-RT & 60 & CCTAACTCTTCGGTGTATGCGGGAC \\
BsGPx3F & 58 & CGTCGCTACAAGACAAGGTGG \\
BsGPx3R & 55 & ACATCTCCAACGCAAGTCC \\
BsGPx3R-RT & 59.3 & GGAAGCCACGACACCTTGC \\
BsSODF & 58.4 & CCACGGGTTTCACATTCACGAG \\
BsSODR & 60.9 & AATCCAATCACGCCACACGCC \\
BsSODF-RT & 60 & CTGTGCAAGGACTGACTCCA \\
BsSODR-RT & 60 & CCGGCATGATCAACCTTAGT \\
BsACTF-RT & 60 & ACTGGGACGACATGGAGAAG \\
BsACTR-RT & 60 & GCTTCTGTGAGGAGGACAGG \\
M13F & 55 & TTGTAAAACGACGGCCAGT \\
M13R & 50 & CAGGAAACAGCTATGACC \\
dT Anchor & 57 & ACCACGCGTATCGATGTCG (dT)16 \\
Anchor & 57 & ACCACGCGTATCGATGTCG \\
\hline
\end{tabular}

PCR, polymerase chain reaction.

Total RNA was isolated from B. schlosseri colonies using the SV Total RNA Isolation System (Promega Corp., Madison, WI); its purity was determined spectrophotometrically by the $A_{260} / A_{280}$ and $A_{260} / A_{230}$ ratios. The integrity of RNA preparation was checked by visualizing the rRNA in ethidium bromide-stained $1.5 \%$ agarose gels. The first strand of cDNA was reverse-transcribed from $1 \mu \mathrm{g}$ of total RNA according to the Improm II manual (Promega Corp.). cDNA amplification was performed with Go-Taq Polymerase (Promega; $5 \mathrm{U} / \mu \mathrm{l}$ ), using the following cycling parameters: $94^{\circ} \mathrm{C}$ for $2 \mathrm{~min}, 40 \mathrm{cy}-$ cles of $94^{\circ} \mathrm{C}$ for $30 \mathrm{~s}$, melting temperature (Tm) for $30 \mathrm{~s}$ (Tms for the various primers are shown in Table 1 ), $72^{\circ} \mathrm{C}$ for $1 \mathrm{~min}$, and, a last step, at $72{ }^{\circ} \mathrm{C}$ for $10 \mathrm{~min}$. Amplicons were subjected to electrophoresis and the corresponding bands were purified with ULTRAPrep Agarose Gel Extraction Mini Prep Kit (AHN Biotechnologie GmbH, Nordhausen, Germany), ligated in pGEM T-Easy Vector (Promega Corp.), and cloned in DH-5 $\alpha$ Escherichia coli cells (Tang et al., 1994). To confirm the sequences and their expression, positively screened clones were sequenced at BMR Genomics (University of Padova) on an ABI PRISM 3700 DNA Analyzer (Applied Biosystems, Inc., Foster City, CA). Gene reconstructions were based on a B. schlosseri database using Spidey's algorithm (http://www.ncbi.nlm.nih.gov/spidey/). 


\section{Quantitative real-time PCR ( $q R T-P C R)$}

To estimate the total amount of mRNA for BsGCLM, BsGS, BsCu/Zn-SOD, BsGPx3, and BsGPx5, we used the qRT-PCR with the SYBR green method (FastStart Universal SYBR Green Master-Rox, Roche Molecular Systems, Inc.). In the first experimental series, mRNA was extracted from three colonies at take-over and three at mid-cycle (reference colonies) and maintained in FSW, to evaluate transcription changes under physiological conditions. In the second series, colonies at $\mathrm{MC}$ were exposed to $0.2 \mu \mathrm{mol}^{-1} \mathrm{CdCl}_{2}$ for 2,4 , and $6 \mathrm{~h}$, and mRNA was extracted from three colonies for each exposure time. mRNA from three unexposed colonies $(\mathrm{Cd}$ concentration $=0)$ was used as reference control. Forward and reverse primers for BsGCLM (BsGCLF-RT and BsGCLR-RT), BsGS (BsGSF-RT and BsGSR-RT), BsCu/ Zn-SOD (BsSODF-RT and BsSODR-RT), BsGPx3 (BsGPx3F and BsGPx3R-RT), BsGPx5 (BsGPx5F-RT and BsGPx5R$\mathrm{RT}$ ), and Bs $\beta$-actin (BsACTF-RT and BsACTR-RT) transcripts - the last one (Bs $\beta$-actin) used as a housekeeping gene-were synthesized by Sigma-Aldrich (St. Louis, MO) (Table 1). The stable expression of $\mathrm{Bs} \beta$-actin level (Campagna et al., 2016) explains the choice of cytoplasmic actin as reference gene for quantitative PCR experiments. To exclude contamination by genomic DNA, all of the designed primers contained parts of contiguous exons; a qualitative PCR was also carried out before qRT-PCR. Furthermore, analysis of the dissociation curve of the qRT-PCR gave no indication of the presence of contaminating DNA.

qRT-PCR analyses were performed using Applied Biosystems 7900 HT Fast Real-Time PCR System, using the following cycling parameters: $95{ }^{\circ} \mathrm{C}$ for $10 \mathrm{~min}$, then 40 cycles of $95^{\circ} \mathrm{C}$ for $10 \mathrm{~s}$ and $60{ }^{\circ} \mathrm{C}$ for $1 \mathrm{~min}$. cDNA synthesis was carried out as described above. Each set of samples was run three times and each plate contained cDNA from three different biological samples $(n=3)$ and negative controls. The $2^{-\Delta \Delta C_{\mathrm{T}}}$ method (Livak and Schmittgen, 2001) was used to estimate the total amount of mRNA. The amounts of transcripts in different conditions were normalized to $\beta$-actin to compensate for variations in the amounts of cDNA.

\section{Sequence alignment and phylogenetic analyses}

Amino acid sequences of the proteins of interest were obtained by in silico translation. Sequence alignment and phylogenetic analyses were performed to compare the obtained sequences with those of the corresponding proteins from metazoans (Supplementary Table 1, view online). Alignments were carried out with Clustal W software (Larkin et al., 2007) and assessed using the Molecular Evolutionary Genetics Analysis (MEGA) ver. 6 program (Tamura et al., 2013) to infer evolutionary relationships among the various orthologous isoforms.

Phylogenetic reconstructions were performed according to unweighted pair group with arithmetic mean (UPGMA; Sneath and Sokal, 1973), minimum evolution (ME; Rzhetsky and Nei, 1992), neighbor-joining (NJ; Saitou and Nei, 1987), maximum parsimony (MP; Sourdis and Nei, 1988), and maximum likelihood (ML; Guindon and Gascuel, 2003) methods.

\section{In situ hybridization (ISH)}

For localization of mRNAs, sense and antisense probes for BsGCLM, BsGS, BsCu/Zn-SOD, BsGPx3, and BsGPx5 transcripts were obtained using T7 RNA- and SP6 RNApolymerase. Probes were further purified with mini Quick Spin Columns (Roche Molecular Systems, Inc.). Whole colonies at MC (both Cd-treated and untreated) as well as hemocytes were used for ISH. Hemocytes, prepared as described above (see Hemocyte collection above in Materials and Methods), were left to adhere to Superfrost Plus slides (Thermo Fisher Scientific, Waltham, MA) for $30 \mathrm{~min}$. Colonies and hemocytes were fixed in freshly prepared MOPS buffer $(0.1 \mathrm{~mol}$ $1^{-1}$ MOPS, $1 \mathrm{mmol} \mathrm{l}^{-1} \mathrm{MgSO}_{4}, 2 \mathrm{mmol} \mathrm{l}^{-1}$ EGTA, and $0.5 \mathrm{~mol}^{-1} \mathrm{NaCl}$ ) and $4 \%$ paraformaldehyde for $30 \mathrm{~min}$ and $2 \mathrm{~h}$, respectively. After a prehybridization step in Hybridization Cocktail 50\% Formamide (AMRESCO, Solon, $\mathrm{OH}$ ) for $1 \mathrm{~h}$ at $58{ }^{\circ} \mathrm{C}$, colonies and hemocytes were incubated with sense and antisense probes $(2 \mu \mathrm{g} / \mathrm{ml}$ biotin-labeled riboprobe in Hybridization Cocktail) overnight at $58{ }^{\circ} \mathrm{C}$. They were then incubated with the ABC Complex (Vector Laboratories, Inc., Burlingame, CA), and positivity was revealed by incubation in $0.025 \% \mathrm{DAB}$ and $0.004 \% \mathrm{H}_{2} \mathrm{O}_{2}$ in phosphatebuffered saline (PBS; $8 \mathrm{~g} / 1 \mathrm{NaCl}, 0.2 \mathrm{~g} / \mathrm{K} \mathrm{KCl}, 0.2 \mathrm{~g} / 1 \mathrm{KH}_{2} \mathrm{PO}_{4}$, $1.15 \mathrm{~g} / 1 \mathrm{Na}_{2} \mathrm{HPO}_{4}, \mathrm{pH}$ 7.2) for $10 \mathrm{~min}$. Colonies were then dehydrated, included in Paraplast Plus Xtra (Sigma-Aldrich), and $7-\mu \mathrm{m}$ sections were obtained with a Jung micrometer. Hemocytes were mounted with Acquovitrex (Carlo Erba Reagents, Cornaredo, Italy). Finally, slides were observed under a light microscope at $1250 \times$ magnification.

\section{Statistical analyses}

Each experiment was replicated three times with three independent colonies $(n=3)$; data are expressed as means \pm SD. Multiple comparisons were carried out with ANOVA; means were compared using Duncan's test (Snedecor and Cochran, 1980).

\section{Results}

\section{Gene and transcript organization}

The PCR amplification of BsGCLM produced an amplicon of 535 base pairs (bp). The coding sequence is $870 \mathrm{bp}$ long, and is flanked by $5^{\prime}$-UTR and $3^{\prime}$-UTR regions of 54 and $626 \mathrm{bp}$, respectively (GenBank ID no. KT12002). The sequence includes one exon of 1550 bp (Fig. 1).

Amplification with BsGSF and BsGSR resulted in an amplicon of 304-bp sharing similarity with other deuterostome glutathione synthases (GSs) (GenBank accession no. KT120025). 


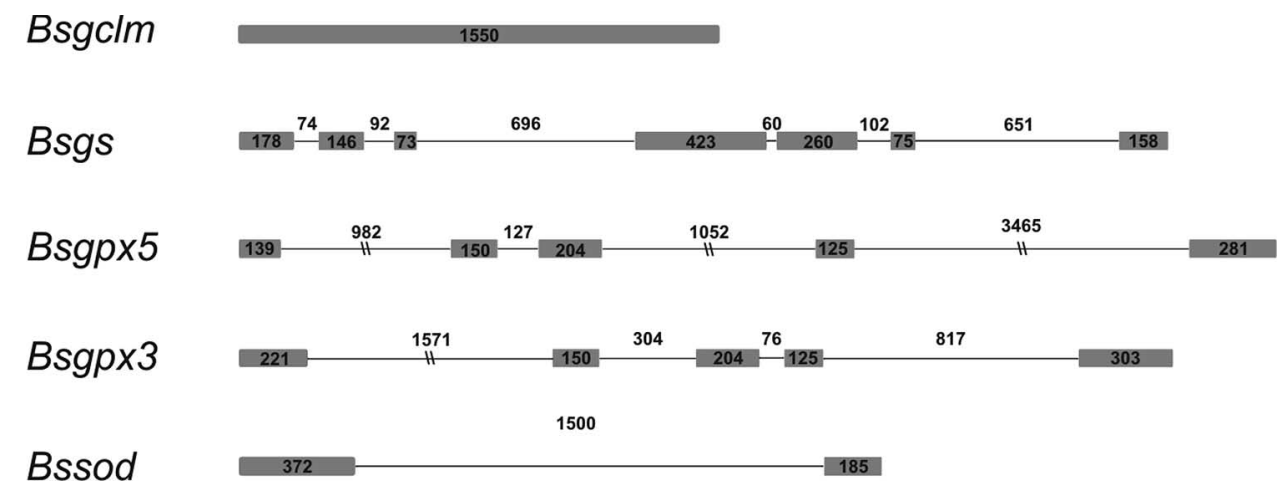

Figure 1. Gene organization of Botryllus schlosseri glutathione synthase (bsgs), B. schlosseri modulatory subunit of $\gamma$-glutamyl-cysteine ligase ( s s $\mathrm{clm}$ ), B. schlosseri $\mathrm{Cu}$-Zn superoxide dismutase (bscu/znsod), and B. Schlosseri glutathione peroxidase 3 (bsgpx3) and 5 (bsgpx5). Exons are denoted by gray rectangles, and introns by lines. Numerals refer to sequence length in base pairs (bps).

The coding sequence consists of $1278 \mathrm{bp}$ and the gene includes 7 exons (Fig. 1) with the ATG start codon located in the first exon and the TAG stop codon in the last exon. All of the introns were provided with the canonical guanine timine (GT) and adenine guanine (AG) splicing signal consensus.

Amplification with BsGPx5F and BsGPx5R produced an amplicon of $493 \mathrm{bp}$ that, after sequencing and BLAST comparison, resulted in vertebrate transcripts similar to those of gpx3 and gpx6. This transcript presents a 675-bp coding sequence, with $5^{\prime}$-UTR and $3^{\prime}$-UTR regions of 58 and $184 \mathrm{bp}$, respectively (GenBank ID no. KT120026). The structure of the gene was analyzed by comparing the cDNA and the genomic sequences. It includes 5 exons (Fig. 1), with the ATG start codon located in the first exon and the TAG stop codon in the last exon. All of the introns were provided with the canonical GT and AG splicing signal consensus.

The PCR amplification with BsGPx3F and BsGPx3R gave an amplicon of $662 \mathrm{bp}$ that, after sequencing and BLAST comparison, resulted in transcripts similar to those of gpxb and gpxc of Ciona intestinalis. The bsgpx 3 transcript has a coding sequence of $636 \mathrm{bp}$, with $5^{\prime}$ UTR and $3^{\prime}$ UTR regions of $128 \mathrm{bp}$ and $239 \mathrm{bp}$, respectively (GenBank accession no. KT120027). The gene structure was analyzed by comparing the cDNA and the genomic sequences. It includes 5 exons (Fig. 1), with the ATG start codon located in the first exon and the TGA stop codon in the last exon. All of the introns were provided with the canonical GT and AG splicing signal consensus.

BsSODF and BsSODR amplified a sequence of $322 \mathrm{bp}$, similar to $\mathrm{Cu} / \mathrm{Zn}$ SOD from other deuterostomes. The coding sequence of this transcript spans $447 \mathrm{bp}$ in length and is flanked by $5^{\prime}$ UTR and $3^{\prime}$ UTR regions of $305 \mathrm{bp}$ and $305 \mathrm{bp}$, respectively (GenBank accession no. KT120028). The structure of the gene was analyzed by comparing the cDNA and the genomic sequences. It includes two exons and one intron (Fig. 1) with canonical GT and AG splicing signal consensus.

\section{Protein organization}

In silico translation of the bsgclm transcript resulted in a putative protein of 289 amino acids with an Aldo/keto reductase superfamily domain extending from residues 85 to 208, required for antioxidant activity (Fig. 2A; Supplementary Fig. 1A, view online). BsGCLM, when aligned with the same protein of other deuterostomes, showed identities ranging from $34.3 \%$ (C. intestinalis) to $28.7 \%$ (Xenopus laevis and Salmo salar) (Supplementary Fig. 1A, view online).

In silico translation of the transcript of bsgs gave a putative protein of 425 amino acids with an eu-GS superfamily domain, typical of glutathione synthases (GSs) and necessary for the creation of the ATP-dependent bond between $\gamma$ glutamylcysteine and glycine, spanning from amino acid 10 to 400 (Fig. 2B; Supplementary Fig. 1B, view online). BsGS, when aligned with the same protein of other deuterostomes, showed identities ranging from $38.8 \%$ (Branchiostoma floridae) to $32.6 \%$ (Danio rerio). By comparing multiple alignments of the predicted amino acid sequence of BsGS with other deuterostome GSs, we recognized the amino acids of the active sites $\left(\mathrm{Met}^{129}, \mathrm{Ile}^{143}, \mathrm{Lys}^{309}, \mathrm{Asn}^{368}, \mathrm{Tyr}^{370}\right.$, the MEKI motif, $\mathrm{Glu}^{427}$, $\mathrm{Lys}^{454}$ ); the ATP-binding amino acids $\left(\mathrm{Ile}^{143}, \mathrm{Lys}^{309}, \mathrm{Val}^{365}, \mathrm{Lys}^{367}\right.$, the MEKI motif, Glu ${ }^{427}, \mathrm{Lys}^{454}$ ); the magnesium-binding sites $\left(\mathrm{Glu}^{144}, \mathrm{Asn}^{146}, \mathrm{Glu}^{371}\right)$; and the GSH-binding sites $\left(\mathrm{Arg}^{123}, \mathrm{Ala}^{148}, \mathrm{Ser}^{150}, \mathrm{Glu}^{215}, \mathrm{Asn}^{217}\right.$, $\mathrm{Gln}^{221}, \mathrm{Arg}^{452}, \mathrm{Val}^{463}, \mathrm{Ala}^{464}$ ), all conserved in the Botryllus schlosseri sequence (Supplementary Fig. 1B, view online).

In silico translation of the transcript of bsgpx 5 resulted in a putative protein of 224 amino acids that included a conserved GSH-peroxidase domain (residues 30-145), necessary for hydroperoxide reduction by GSH, which acts as an electron donor (Fig. 2C; Supplementary Fig. 1C, view online). BsGPx5, when aligned with the same protein of other deuterostomes, showed identities ranging from $34.5 \%$ (C. intestinalis GPxc) to $24.8 \%$ (B. floridae). By comparing multiple alignments of 


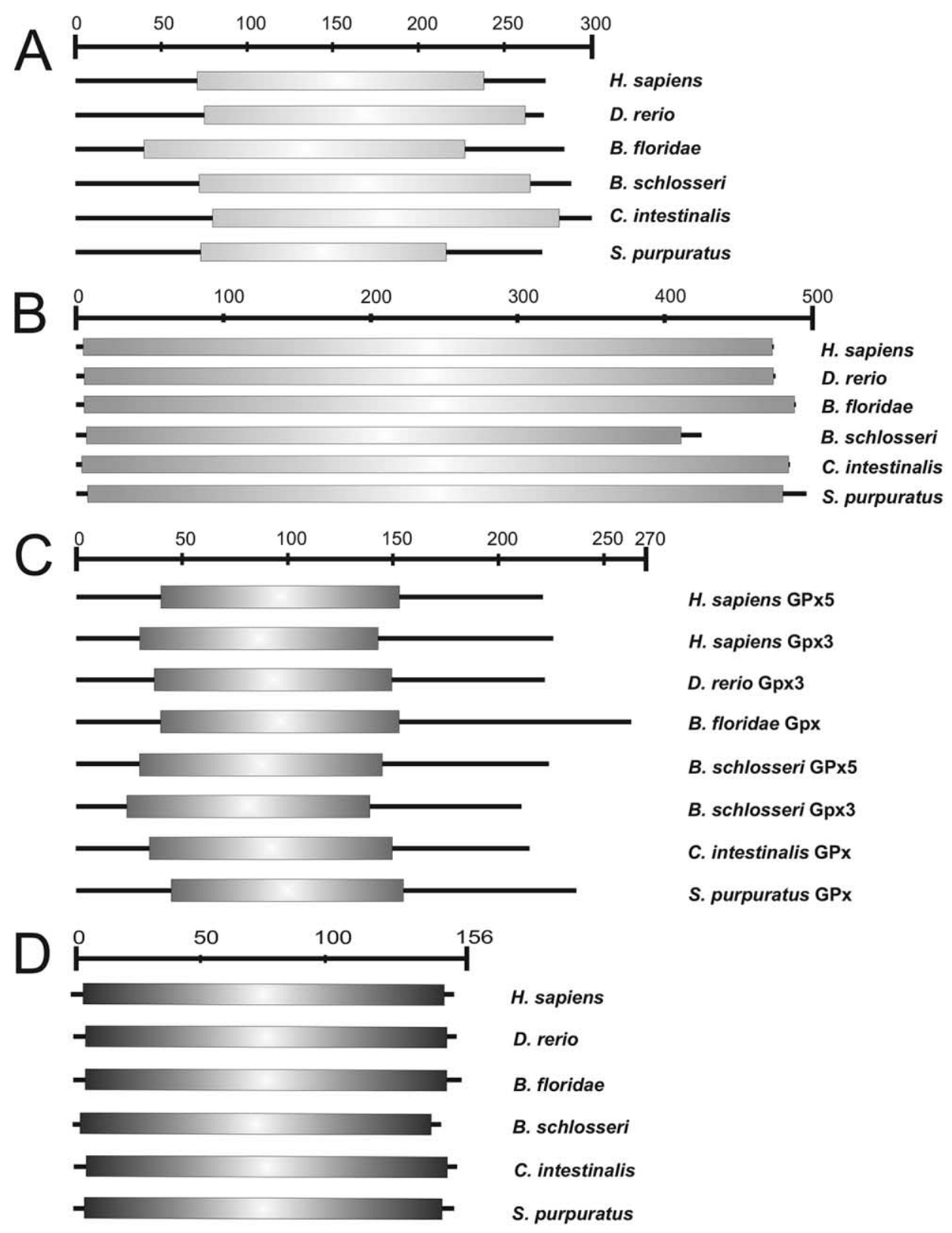

Figure 2. Schematic deuterostome domain organization of the modulatory subunit of $\gamma$-glutamyl-cysteine ligase (GCLM) (A); glutathione synthase (GS) (B); glutathione peroxidase 3 (GPx3) and 5 (GPx5) (C); and Cu-Zn superoxide dismutase $(\mathrm{Cu} / \mathrm{ZnSOD})(\mathrm{D})$ proteins. Numbers refer to the length of the amino acid sequences.

the predicted amino acid sequence of BsGPx5 with other deuterostome GPx, we identified two conserved amino acids of the active sites involved in catalytic activity in other deuterostomes $\left(\mathrm{Gln}^{95}, \operatorname{Trp}^{173}\right)$. Residue 61, aligning with conserved U/C (cysteine with serine/cysteine) in vertebrates, is represented by a Ser, as in B. floridae (Supplementary Fig. 1C, view online).

In silico translation of the bsgpx 3 transcript resulted in a putative protein of 211 amino acids that included a conserved GSH-peroxidase domain, from residue 34 to 149 (Fig. 2C;
Supplementary Fig. 1C, view online). BsGPx3, when aligned with the same protein of other deuterostomes, showed identities ranging from $38.2 \%$ (C. intestinalis GPxb) to $25 \%$ (B. floridae). By comparing multiple alignments of the predicted amino acid sequence of BsGPx3 with those of other deuterostome GPxs, we recognized the three amino acids of the active sites involved in catalytic activity (Sec/Cys ${ }^{161}, \mathrm{Gln}^{95}, \operatorname{Tr}^{173}$ ) (Supplementary Fig. 1C, view online).

In silico translation of the transcript of bscu/znsod resulted in a protein of 148 amino acids, with the $\mathrm{Cu}-\mathrm{Zn}$ superoxide 
dismutase superfamily domain extending from residue 1 to 140 (Fig. 2D; Supplementary Fig. 1D, view online). BsCu/ ZnSOD, when aligned with the same protein of other deuterostomes, showed identities that ranged from $57.9 \%$ (Ovis aries, Bos taurus, Bos grunniens) to $20.5 \%$ (C. intestinalis). By comparing multiple alignment of the predicted amino acid sequence of $\mathrm{BsCu} / \mathrm{ZnSOD}$ with other deuterostome $\mathrm{Cu} /$ ZnSODs, we were able to recognize the amino acids of the active sites that bind cadmium $\left(\mathrm{His}^{41}, \mathrm{His}^{43}\right.$, $\mathrm{His}^{115}$ ), zinc (His ${ }^{66}$, $\mathrm{His}^{75}$ ), zinc and cadmium $\left(\mathrm{His}^{58}\right)$, as well as those involved in antioxidant reactions $\left(\mathrm{Thr}^{132}, \mathrm{Arg}^{138}\right)$ (Supplementary Fig. 1D, view online).

\section{Phylogenetic analyses}

Phylogenetic trees were obtained from multiple alignments, using Clustal $\mathrm{W}$ on the predicted amino acid sequences of each considered transcript. All of the methods used gave similar results, but only trees that were obtained using maximum likelihood (ML) are presented. Trees of GCLM and GS showed that the tunicate cluster, represented by Botryllus schlosseri and Ciona intestinalis, is always positioned close to the cephalocordate + vertebrate clade (Figs. 3, 4).

As regards the phylogenetic reconstruction of deuterostome GPxs, BsGPx5 clusters together with $C$. intestinalis GPxc and Xenopus laevis, Xenopus tropicalis, and Danio rerio GPx3, as the sister group of vertebrate GPx1, GPx2, and GPx4 (Supplementary Fig. 2, view online), whereas BsGPx3 groups with C. intestinalis GPxc, X. laevis, and X. tropicalis GPx3, and Branchiostoma floridae GPx (Supplementary Fig. 3, view online). BsSOD clusters with $B$. floridae SOD; $C$. intestinalis SOD appears unrelated to the vertebrate group (Fig. 5).

\section{$q R T-P C R$}

When analyzed in the course of the blastogenetic cycle, the total amount of mRNAs for BsGCLM, BsCu/ZnSOD, and BsGPx5 significantly $(P<0.001)$ decreased during take-over with respect to MC. Conversely, BsGPx3, in the same conditions, significantly $(P<0.001)$ increased its mRNA level. The amount of mRNA for BsGS did not significantly change during TO phase with respect to mid-cycle (Fig. 6A).

Upon cadmium (Cd) exposure, the relative expression of the considered genes was deeply regulated. The quantity of mRNAs of bscu/znsod, bsgpx3, and bsgs that resulted were significantly $(P<0.05)$ increased, reaching the maximum amount of mRNAs, from 3- to 13-fold induction, after $2 \mathrm{~h}$ of treatment with $\mathrm{Cd}$. The quantity then gradually decreased, with the lowest value seen at $6 \mathrm{~h}$ of treatment. Conversely, the level of mRNAs for BsGCLM and BsGPx5 decreased with respect to the control; BsGPx5 returned to the control value after 6 h (Fig. 6B).
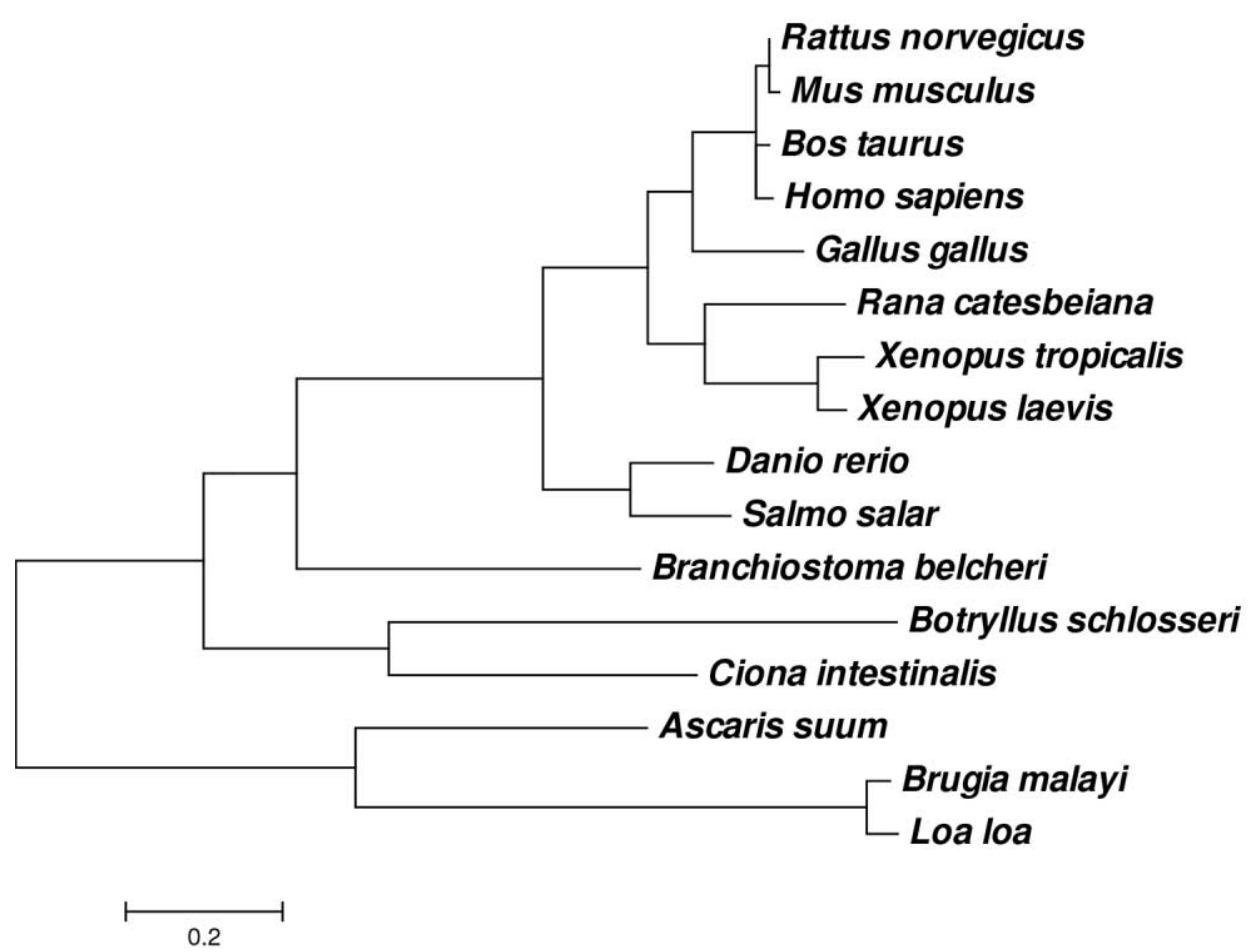

Figure 3. Evolutionary relationships (maximum likelihood; ML) among metazoan modulatory subunits of $\gamma$ glutamyl-cysteine ligases (GCLMs). Similar topologies were obtained with neighbor-joining (NJ), minimum evolution (ME), and unweighted pair groups with arithmetic mean (UPGMA). Branch length scale $=0.2$ substitutions per site. 

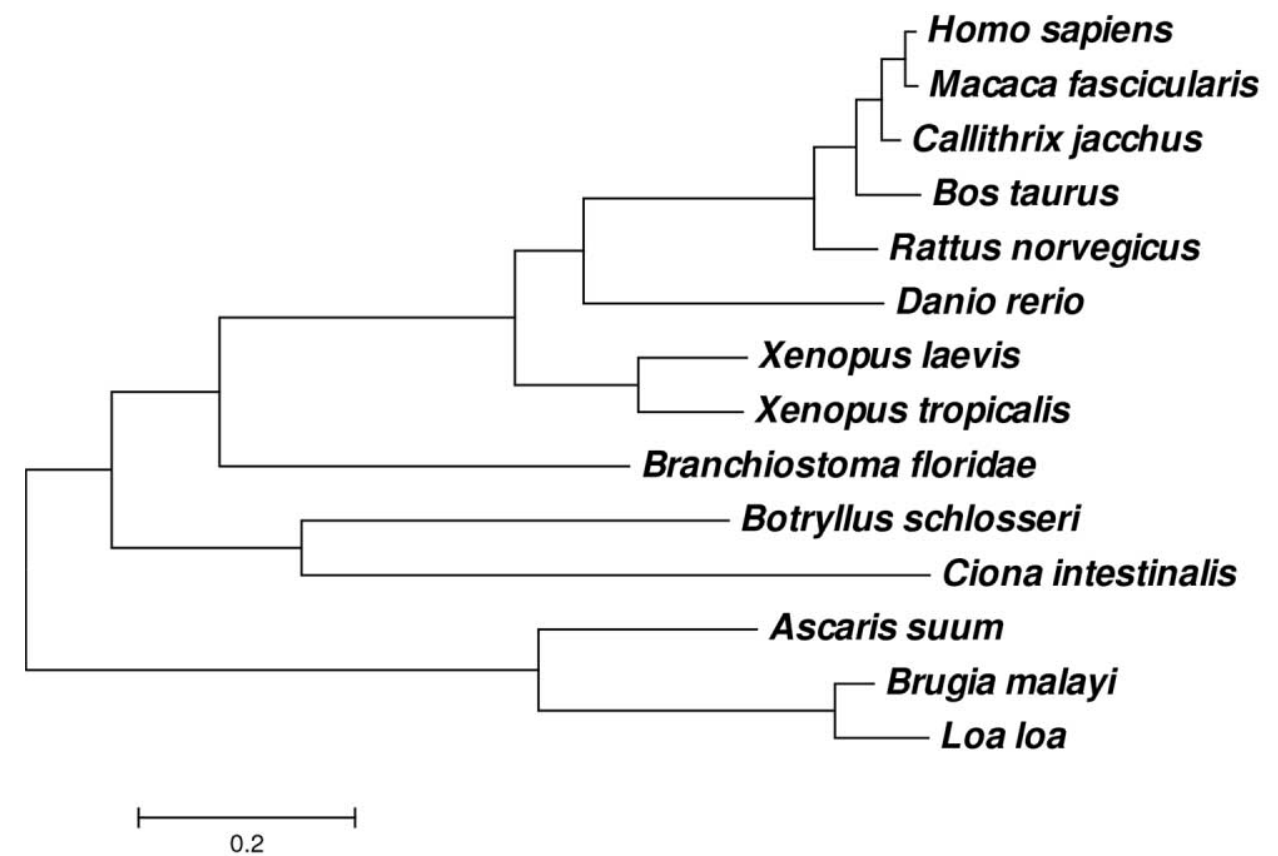

Figure 4. Evolutionary relationships (maximum likelihood; ML) among metazoan glutathione synthases (GSs). Similar topologies were obtained with neighbor-joining (NJ), minimum evolution (ME), and unweighted pair groups with arithmetic mean (UPGMA). Branch length scale $=0.2$ substitutions per site.

In-situ hybridization

In colony sections, only hemocytes contained detectable levels of transcripts for BsGCLM, BsGS, BsCu/ZnSOD, BsGPx3, and BsGPx5 (data not shown). A more detailed analysis of hemocyte smears revealed that only immunocytes were labeled. In the presence of the specific riboprobes for BsGCLM and BsGPx3, cytotoxic morula cells and phagocytes were labeled, the former (BsGCLM) prevailing at take-over, and BsGPx3 prevailing at mid-cycle. Morula cells, at takeover, and phagocytes, at mid-cycle and take-over, were also recognized by antisense probes for BsGS and $\mathrm{BsCu} / \mathrm{ZnSOD}$, whereas only phagocytes were labeled by the probe for BsGPx 5 (at mid-cycle and take-over). In addition, undifferentiated young cells, also called hemoblasts, appeared stained with the specific probes for GPx 5 and $\mathrm{Cu} / \mathrm{ZnSOD}$ in both mid-cycle and take-over. Incubation with the sense probes gave no labeling of the cells (Fig. 7).

\section{Discussion}

Despite the phylogenetic position of tunicates as the vertebrate sister group, their stress responses have been poorly investigated until now. A limited but increasing body of evidence indicates that ascidian hemocytes play important roles in stress responses by producing antioxidant molecules able to counteract the stress-related increase of ROS production (Franchi et al., 2011, 2012, 2014; Ferro et al., 2013).
In the compound ascidian Botryllus schlosseri, high quantities of ROS are produced both during the non-fusion reaction between genetically incompatible colonies, resulting in diffuse cytotoxicity along the contact region (Ballarin et al., 2002) and at take-over, as a consequence of the increased respiratory burst in phagocytes that have ingested apoptotic cells and corpses deriving from the tissues of the old zooids (Cima et al., 2010; Franchi et al., 2016). In both processes, hemocytes are directly involved. Although some of them undergo ROS-induced cell death, most hemocytes do not die, suggesting their ability to overcome unfavorable conditions.

In the present work, we identified and characterized the transcripts for five Botryllus schlosseri enzymes (BsSOD, BsGCLM, BsGS, BsGPx3, and BsGPx5) involved in ROS detoxification mechanisms. To our knowledge, this is the first study of these genes in Botryllus. In addition, we demonstrated the modulation of the transcription of the abovereported genes during take-over and on exposure to cadmium. In both cases, increased production of ROS has been reported (Cima et al., 2010; Franchi and Ballarin, 2013). This suggests that oxidative stress is the cause of the observed gene modulation and that cells face an increasing level of ROS by producing thiol-containing molecules, such as glutathione (GSH), or antioxidant enzymes. The location of the transcripts in immunocytes, as revealed by in situ hybridization, supports our previous observations in the solitary ascidian Ciona intestinalis (Franchi et al., 2011, 2012, 2014; Ferro et al., 2013), indicating that, in the absence of detoxifying or- 


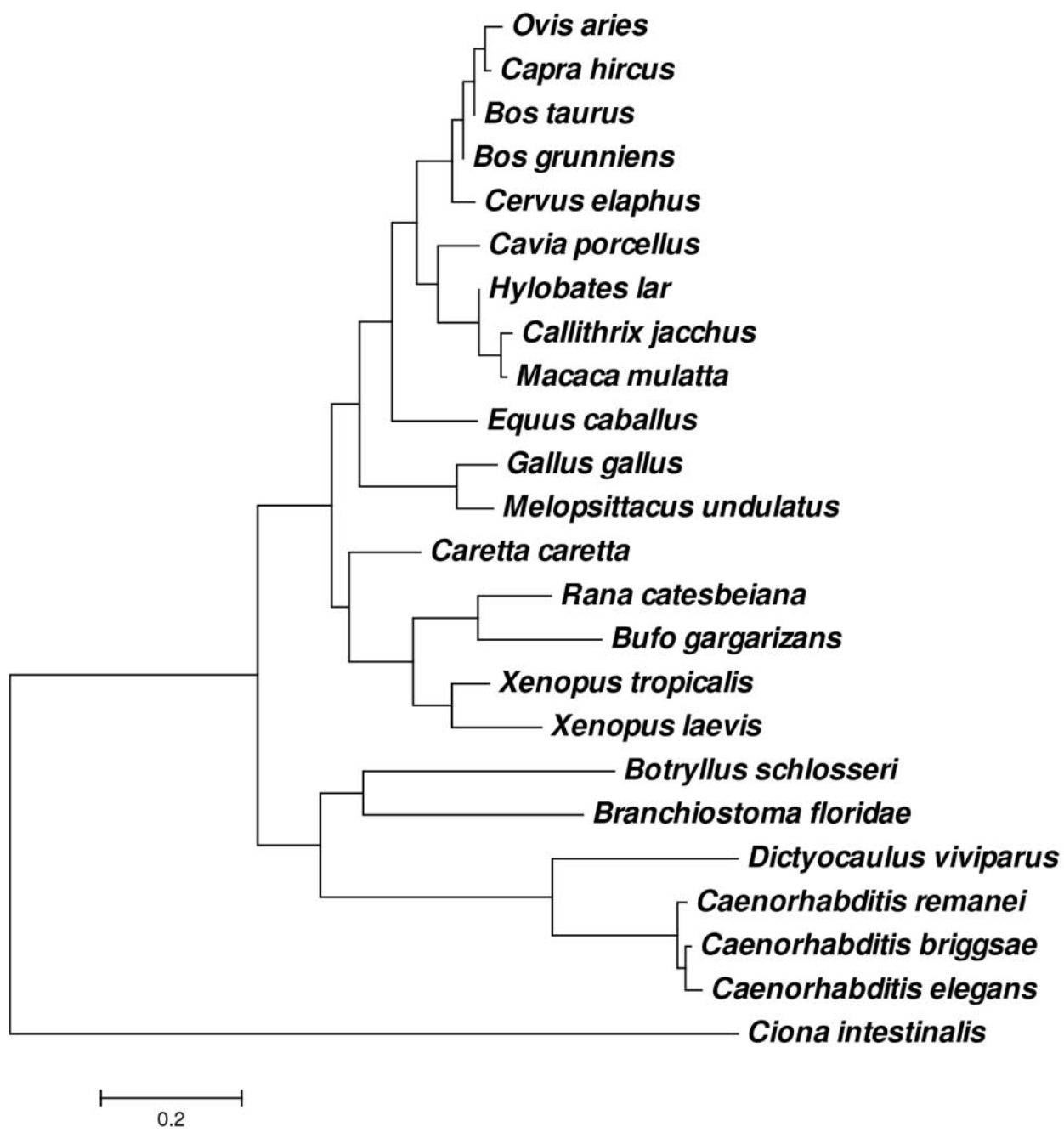

Figure 5. Evolutionary relationships (maximum likelihood; ML) among deuterostome glutathione peroxidase (GPxs). Similar topologies were obtained with neighbor-joining (NJ), minimum evolution (ME), and unweighted pair groups with arithmetic mean (UPGMA). Branch length scale $=0.2$ substitutions per site.

gans, hemocytes represent the main detoxification system of tunicates. The reported presence of some transcript-related labeling in young hemocytes probably marks their first steps towards fully differentiated circulating cells.

The main intracellular antioxidant molecule is represented by GSH, a tripeptide ( $\gamma$-glutamylcysteinylglycine) with a thiol group able to react with ROS, resulting in the formation of oxidized GSH (GSSG). In mammals, the synthesis of GSH involves two ATP-dependent reactions catalyzed by different enzymes. The first is $\gamma$-glutamyl-cysteine ligase (GCL), composed of a catalytic and a modulatory subunit (GCLC and GCLM, respectively) (Griffith, 1999; Dickinson and Forman, 2002). The second enzyme is glutathione synthase (GS), which catalyzes the binding of L-glycine to previously formed $\gamma$-glutamylcysteine. The transcripts for both genes are present in Botryllus immunocytes, either in phagocytes or morula cells. The amount of transcripts for BsGCLM decreases dur- ing take-over, as well as during Cd-treatment, suggesting a weak contribution of this subunit and, consequently, a probable major role of GCLC in the regulation of GSH synthesis in B. schlosseri. The increase in the amount of mRNA for BsGS in hemocytes from Cd-exposed colonies is probably due to Cd-induced oxidative stress, in accordance with the known induction of GSH synthesis by ROS (Franchi et al., 2012; Jeppe et al., 2014). In contrast, the absence of modulation in the level of transcript for BsGS, during the generation change, probably represents the equilibrium between the increase in gene expression, as a consequence of oxidative stress, and the decrease in the total number of aged cells as a consequence of apoptosis at take-over.

Among the detoxifying enzymes, superoxide dismutase (SOD) catalyzes a redox reaction, converting superoxide anions into molecular oxygen and hydrogen peroxide (Fridovich, 1986). GPxs, however, catalyze the reduction of peroxides 


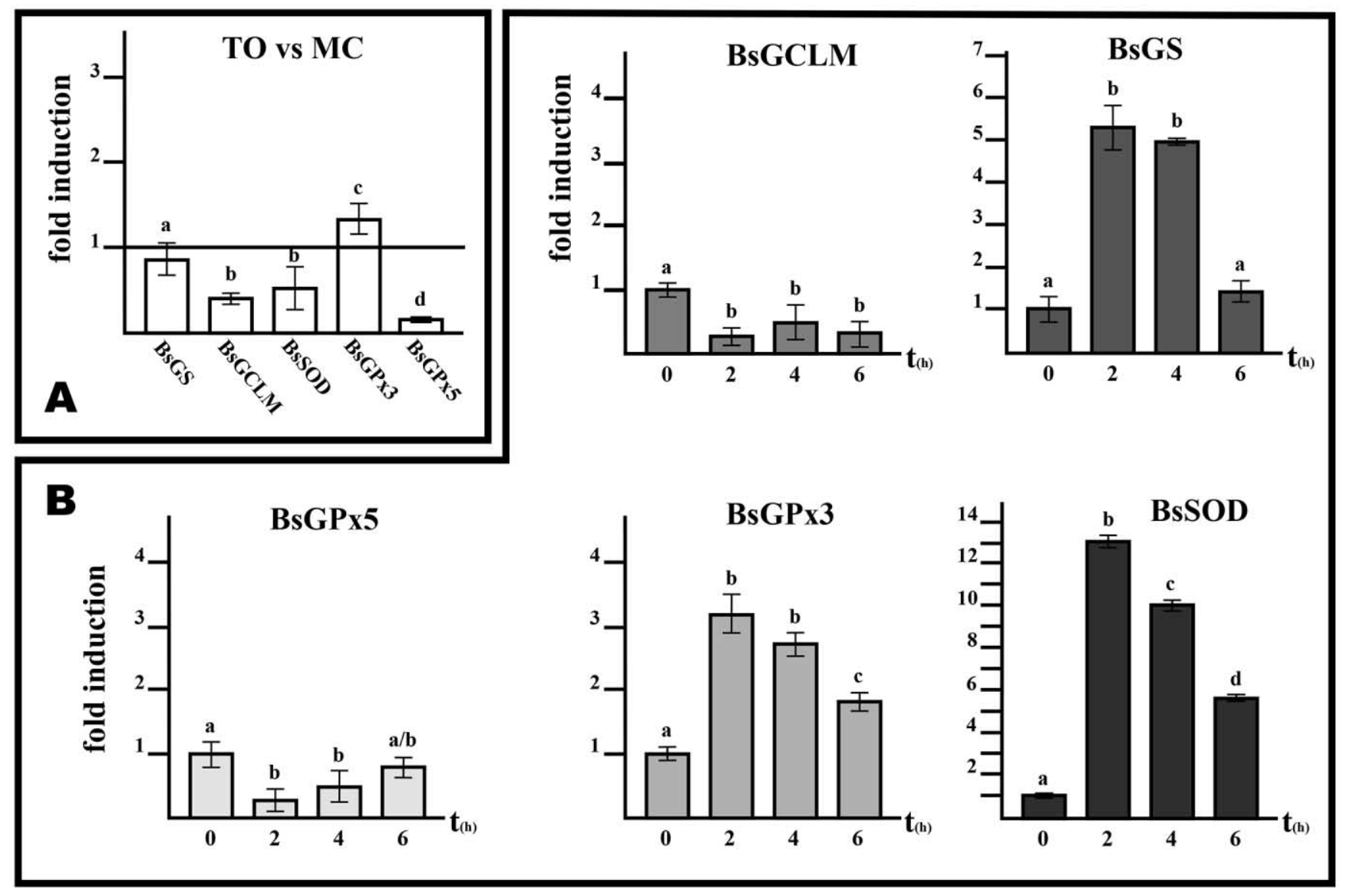

Figure 6. (A) Relative levels of mRNA in five Botryllus schlosseri enzymes: glutathione synthase (BsGS), B. schlosseri subunit of $\gamma$-glutamyl-cysteine ligase (BsGCLM), B. schlosseri $\mathrm{Cu}-\mathrm{Zn}$ superoxide dismutase (BsCu/ $\mathrm{ZnSOD}$ ), and B. schlosseri glutathione peroxidase 3 (BsGPx3) and 5 (BsGPx5) at take-over with respect to midcycle (MC; reference control set to 1). (B) Relative levels of mRNA for BsGS, BsGCLM, BsCu/ZnSOD, BsGPx3, and BsGPx5 after treatment with $0.2 \mu \mathrm{mol} \mathrm{l}^{-1} \mathrm{CdCl}_{2}$ with respect to unexposed colonies $(\mathrm{Cd}$ concentration $=0$; reference control set to 1). Normalization of expression was achieved using endogenous $\beta$-actin as housekeeping gene. Each histogram bar corresponds to the average of three independent experiments, each with a different colony $(n=3) \pm \mathrm{SD}$. Different letters denote significant $(P<0.05)$ differences from the reference control. TO, take-over.

using GSH as substrate (Sunde and Hoekstra, 1980). Members of the GPx family can include a selenocysteine (SEC) residue in their $N$-terminal region. This residue is related to the presence of a SEC insertion sequence (SECIS) in the corresponding mRNA that allows the translation of the UGA codon of the catalytic site as SEC instead of as a STOP codon (BrigeliusFlohé, 1999; Brigelius-Flohé and Maiorino, 2013). In mammals, eight types of GPx have been identified so far (Brigelius-Flohé and Maiorino, 2013), expressed in various tissues (Ghyselinck et al., 1993; Arthur, 2000; Toppo et al., 2008; Brigelius-Flohé and Maiorino, 2013).

As stated earlier, our results indicated that the transcripts of these enzymes change during take-over and upon $\mathrm{Cd}$ exposure. For $\mathrm{Cd}$, we observed an increase in the amount of mRNA for BsGS, BsGPx3, and BsCu/ZnSOD in exposed colonies. This finding is in agreement with the results ob- tained in solitary ascidians, which saw an increase in the transcription of genes for GCLC, GCLM, GS, metallothioneins, phytochelatin synthase, and $\mathrm{SODb}$ in Ciona intestinalis after treatment with $10 \mu \mathrm{mol} \mathrm{l}^{-1} \mathrm{CdCl}_{2}$ (Franchi et al., 2011, 2012, 2014; Ferro et al., 2013). The metal, cadmium, can deeply influence cysteine metabolism, acting at the level of the trans-sulfuration pathway, and cysteine is essential in detoxification processes because the amino acid is required for the synthesis of nonenzymatic, thiol-rich molecules, such as GSH, metallothioneins, and phytochelatins (Hughes et al., 2009; Jeppe et al., 2014).

The identified $\mathrm{BsCu} / \mathrm{ZnSOD}$ lacks the signal peptide and can be considered an intracellular enzyme. According to the in silico hybridization results, its mRNA is located in morula cells and phagocytes. The lower amount of transcript at takeover is probably related to the fact that the transcripts are 


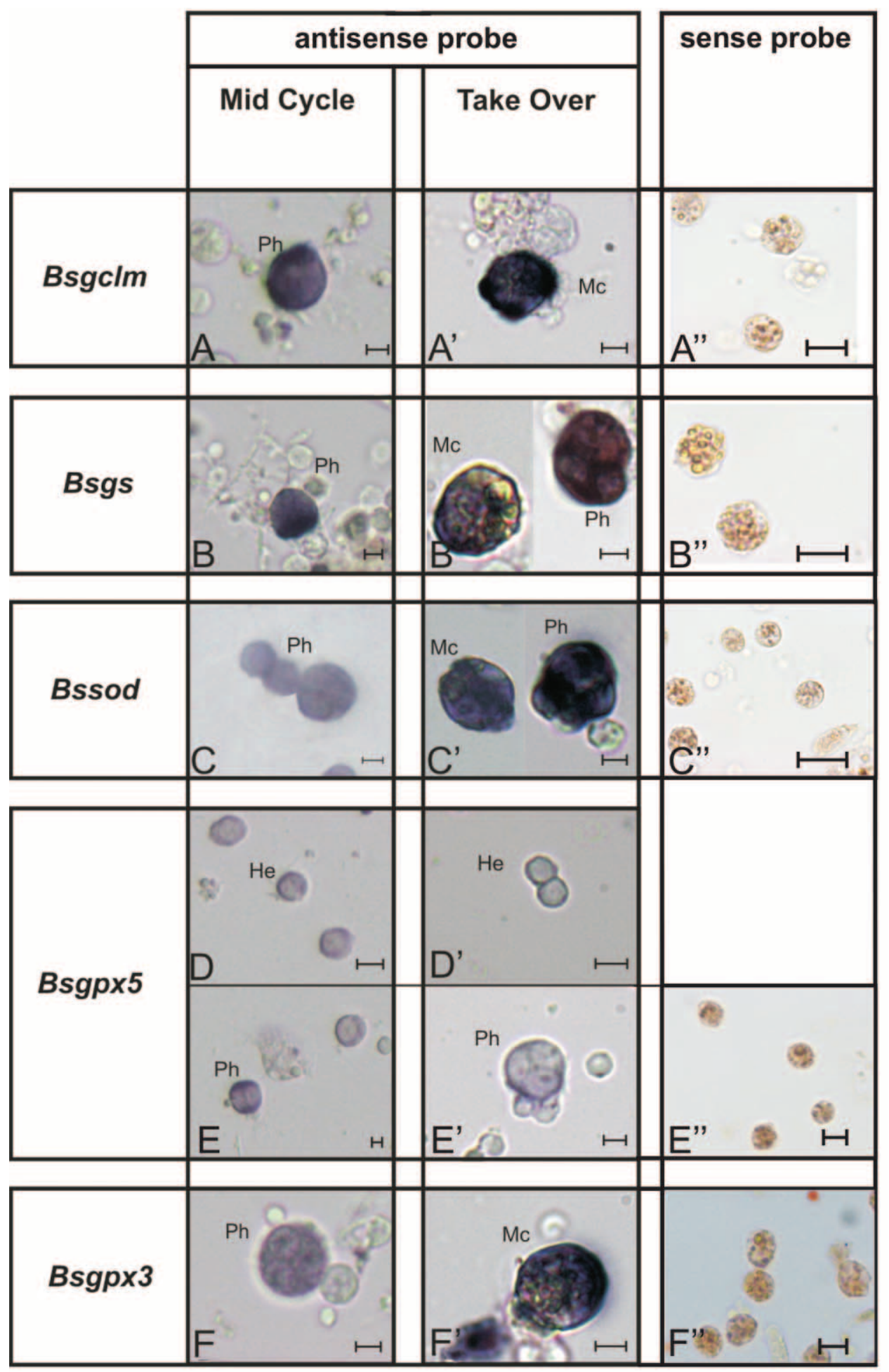

Figure 7. In silico hybridization of hemocytes stained with antisense riboprobes for transcripts of bsgclm, bsgs, bscu/znsod, bsgpx3, and bsgpx5 in mid-cycle (A-F) and at take-over $\left(\mathrm{A}^{\prime}-\mathrm{F}^{\prime}\right)$. A"-F": sense probes (control). He, hemoblast; Mc, morula cell; Ph, phagocyte. Scale bar $=5 \mu \mathrm{m}$. 
present in mature immunocytes, most of which, in this phase of the colonial blastogenetic cycle, undergo cell death by apoptosis (Cima et al., 2010). However, the gene is activated by $\mathrm{Cd}$ exposure, resulting in an increase in the transcript level, in agreement with what was observed for the intracellular SOD of $C$. intestinalis (Ferro et al., 2013).

GPxs include enzymes with or without the SECIS element, corresponding to a SEC or a Cys residue in the active site of the proteins, respectively. BsGPx 3 shares with vertebrate GPx 3 and GPx6 the presence of the SECIS. In addition, like vertebrate GPx3, BsGPx3 has the signal peptide that is absent in vertebrate GPx6. BsGPx5 lacks the SECIS and presents the signal peptide, as with vertebrate GPx5. What is unusual in BsGPx 5 is the substitution of a Cys with a Ser residue, which has no reported antioxidant activity, in the catalytic site. The mRNA of both enzymes is mainly located in phagocytes, with BsGPx 3 mRNA detectable only during the mid-cycle, when most of the phagocytes assume the spreading morphology and are not massively involved in phagocytosis (Ballarin et al., 1994).

Different structure, pattern of expression, and response to $\mathrm{CdCl}_{2}$ treatment strongly suggest different roles for the two BsGPx enzymes, with BsGPx3 more active in oxidative stress response and BsGPx5 probably involved in cellular homeostasis. This fits the observed increase in the amount of the mRNA for BsGPx3 at the generation change and in the presence of $\mathrm{Cd}$, both the situations being marked by high ROS production. The decrease of the transcript level for BsGPx5, as detected by qRT PCR, at the take-over can be related to the decrease in the number of mature phagocytes in the colonial circulation.

Since changes in the amount of total mRNA do not necessarily correlate with changes in protein synthesis, these transcriptional data need to be augmented by quantification of the products (e.g., through the measure of enzyme activity), the focus of future research.

\section{Acknowledgments}

This work was supported by the Italian Ministry of Education, Universities and Research (MIUR; Prin 2010/11, 20109XZEPR).

\section{Literature Cited}

Abe, Y., G. Ishikawa, H. Satoh, K. Azumi, and H. Yokosawa. 1999. Primary structure and function of superoxide dismutase from the ascidian Halocynthia roretzi. Comp. Biochem. Physiol. B Biochem. Mol. Biol. 122: 321-326.

Arthur, J. R. 2000. The glutathione peroxidases. Cell. Mol. Life Sci. 57: 1825-1835

Ballarin, L., and F. Cima. 2005. Cytochemical properties of Botryllus schlosseri haemocytes: indications for morpho-functional characterisation. Eur. J. Histochem. 49: 255-264
Ballarin, L., F. Cima, and A. Sabbadin. 1994. Phagocytosis in the colonial ascidian Botryllus schlosseri. Dev. Comp. Immunol. 18: 467-481.

Ballarin, L., A. Franchini, E. Ottaviani, and A. Sabbadin. 2001. Morula cells as the major immunomodulatory hemocytes in ascidians: evidence from the colonial species Botryllus schlosseri. Biol. Bull. 201: $59-64$.

Ballarin, L., F. Cima, M. Floreani, and A. Sabbadin. 2002. Oxidative stress induces cytotoxicity during rejection reaction in the compound ascidian Botryllus schlosseri. Comp. Biochem. Physiol. C Toxicol. Pharmacol. 133: 411-418.

Ballarin, L., P. Burighel, and F. Cima. 2008a. A tale of death and life: natural apoptosis in the colonial ascidian Botryllus schlosseri (Urochordata, Ascidiacea). Curr. Pharm. Des. 14: 138-147.

Ballarin, L., A. Menin, L. Tallandini, V. Matozzo, P. Burighel, G. Basso, E. Fortunato, and F. Cima. 2008b. Haemocytes and blastogenetic cycle in the colonial ascidian Botryllus schlosseri: a matter of life and death. Cell Tissue Res. 331: 555-564.

Ballarin, L., F. Schiavon, and L. Manni. 2010. Natural apoptosis during the blastogenetic cycle of the colonial ascidian Botryllus schlosseri: a morphological analysis. Zool. Sci. 27: 96-102.

Brigelius-Flohé, R. 1999. Tissue-specific functions of individual glutathione peroxidases. Free Radic. Biol. Med. 27: 951-965.

Brigelius-Flohé, R., and M. Maiorino. 2013. Glutathione peroxidases. Biochim. Biophys. Acta 1830: 3289-3303.

Campagna, D., F. Gasparini, N. Franchi, N. Vitulo, F. Ballin, L. Manni, G. Valle, and L. Ballarin. 2016. Transcriptome dynamics in the asexual cycle of the chordate Botryllus schlosseri. BMC Genomics 17: 275.

Canesi, L. 2015. Pro-oxidant and antioxidant processes in aquatic invertebrates. Ann. N. Y. Acad. Sci. 1340: 1-7.

Cima, F., and L. Ballarin. 2009. Apoptosis and pattern of Bcl-2 and Bax expression in the alimentary tract during the colonial blastogenetic cycle of Botryllus schlosseri (Urochordata, Ascidiacea). Ital. J. Zool. 76: 28-42.

Cima, F., G. Basso, and L. Ballarin. 2003. Apoptosis and phosphatidylserinemediated recognition during the take-over phase of the colonial life-cycle in the ascidian Botryllus schlosseri. Cell Tissue Res. 312: 369-376.

Cima, F., A. Sabbadin, and L. Ballarin. 2004. Cellular aspects of allorecognition in the compound ascidian Botryllus schlosseri. Dev. Comp. Immunol. 28: 881-889.

Cima, F., L. Manni, G. Basso, E. Fortunato, B. Accordi, F. Schiavon, and L. Ballarin. 2010. Hovering between death and life: natural apoptosis and phagocytes in the blastogenetic cycle of the colonial ascidian Botryllus schlosseri. Dev. Comp. Immunol. 34: 272-285.

De la Fuente, M., and V. M. Victor. 2000. Anti-oxidants as modulators of immune function. Immunol. Cell Biol. 78: 49-54.

Delsuc, F., H. Brinkmann, D. Chourrout, and H. Philippe. 2006. Tunicates and not cephalochordates are the closest living relatives of vertebrates. Nature 439: 965-968.

Dickinson, D. A., and H. J. Forman. 2002. Cellular glutathione and thiols metabolism. Biochem. Pharmacol. 64: 1019-1026.

Ferro, D., N. Franchi, V. Mangano, R. Bakiu, M. Cammarata, N. Parrinello, G. Santovito, and L. Ballarin. 2013. Characterization and metal-induced gene transcription of two new copper zinc superoxide dismutases in the solitary ascidian Ciona intestinalis. Aquat. Toxicol. 140-141: 369-379.

Franchi, N., and L. Ballarin. 2013. Influence of cadmium on the morphology and functionality of haemocytes in the compound ascidian Botryllus schlosseri. Comp. Biochem. Physiol. C Toxicol. Pharmacol. 158: 29-35.

Franchi, N., F. Boldrin, L. Ballarin, and E. Piccinni. 2011. CiMT-1, an unusual chordate metallothionein gene in Ciona intestinalis genome: structure and expression studies. J. Exp. Zool. A Ecol. Genet. Physiol. 315A: $90-100$.

Franchi, N., D. Ferro, L. Ballarin, and G. Santovito. 2012. Transcription of genes involved in glutathione biosynthesis in the solitary 
tunicate Ciona intestinalis exposed to metals. Aquat. Toxicol. 114-115: $14-22$.

Franchi, N., E. Piccinni, D. Ferro, G. Basso, B. Spolaore, G. Santovito, and L. Ballarin. 2014. Characterization and transcription studies of a phytochelatin synthase gene from the solitary tunicate Ciona intestinalis exposed to cadmium. Aquat. Toxicol. 152: 47-56.

Franchi, N., L. Ballarin, and F. Cima. 2015. Insights on cytotoxic cells of the colonial ascidian Botryllus schlosseri. Invertebr. Surviv. J. 12: 109-117.

Franchi, N., F. Ballin, L. Manni, F. Schiavon, G. Basso, and L. Ballarin. 2016. Recurrent phagocytosis-induced apoptosis in the cyclical generation change of the compound ascidian Botryllus schlosseri. Dev. Comp. Immunol. 62: 8-16.

Fridovich, I. 1986. Superoxide dismutases. Adv. Enzymol. Relat. Areas Mol. Biol. 58: 61-97.

Gasparini, F., L. Manni, F. Cima, G. Zaniolo, P. Burighel, F. Caicci, N. Franchi, F. Schiavon, F. Rigon, D. Campagna, and L. Ballarin. 2015. Sexual and asexual reproduction in the colonial ascidian Botryllus schlosseri. Genesis 53: 105-120.

Ghyselinck, N. B., I. Dufaure, J. J. Lareyre, N. Rigaudière, M. G. Mattéi, and J. P. Dufaure. 1993. Structural organization and regulation of the gene for the androgen-dependent glutathione peroxidase-like protein specific to the mouse epididymis. Mol. Endocrinol. 7: 258-272.

Griffith, O. W. 1999. Biologic and pharmacologic regulation of mammalian glutathione synthesis. Free Radic. Biol. Med. 27: 922-935.

Guindon, S., and O. Gascuel. 2003. A simple, fast, and accurate algorithm to estimate large phylogenies by maximum likelihood. Syst. Biol. 52: 696-704.

Hughes, S. L., J. G. Bundy, E. J. Want, P. Kille, and S. R. Sturzenbaum. 2009. The metabolomic responses of Caenorhabditis elegans to cadmium are largely independent of metallothionein status, but dominated by changes in cystathionine and phytochelatins. J. Proteome Res. 8: $3512-3519$.

Jeppe, K. J., M. E. Carew, S. M. Long, S. F. Lee, V. Pettigrove, and A. A. Hoffmann. 2014. Genes involved in cysteine metabolism of Chironomus tepperi are regulated differently by copper and by cadmium. Comp. Biochem. Physiol. 162C: 1-6.

Kaloyianni, M., S. Dailianis, E. Chrisikopoulou, A. Zannou, S. Koutsogiannaki, D. H. Alamdari, G. Koliakos, and V. K. Dimitriadis. 2009. Oxidative effects of inorganic contaminants on haemolymph of mussels. Comp. Biochem. Physiol. 149C: 631-639.

Koutsogiannaki, S., S. Franzellitti, S. Kalogiannis, E. Fabbri, V. K. Dimitriadis, and M. Kaloyianni. 2015. Effects of cadmium and $17 \beta$-estradiol on Mytilus galloprovincialis redox status. Prooxidantantioxidant balance (PAB) as a novel approach in biomonitoring of marine environments. Mar. Environ. Res. 103: 80-88.

Larkin, M. A., G. Blackshields, N. P. Brown, R. Chenna, P. A. McGettigan, H. McWilliam, F. Valentin, I. M. Wallace, A. Wilm, R. Lopez et al. 2007. Clustal W and Clustal X version 2.0. Bioinformatics 23: 2947-2948.

Lauzon, R. J., K. J. Ishizuka, and I. L. Weissman. 1992. A cyclical, developmentally regulated death phenomenon in a colonial urochordate. Dev. Dyn. 194: 71-83.
Lauzon, R. J., C. W. Patton, I. L. Weissman. 1993. A morphological and immunohistochemical study of programmed cell death in Botryllus schlosseri (Tunicata, Ascidiacea). Cell Tissue Res. 272: 115-127.

Lesser, M. P. 2006. Oxidative stress in marine environments: biochemistry and physiological ecology. Аппи. Rev. Physiol. 68: 253-278.

Liu, J., Z. X. Zhou, W. Zhang, M. W. Bell, and M. P. Waalkes. 2009. Changes in hepatic gene expression in response to hepatoprotective levels of zinc. Liver Int. 29: 1222-1229.

Livak, K. J., and T. D. Schmittgen. 2001. Analysis of relative gene expression data using real-time quantitative PCR and the $2^{-\Delta \Delta C_{\mathrm{T}}}$ ) method. Methods 25: 402-408.

Manni, L., G. Zaniolo, F. Cima, P. Burighel, and L. Ballarin. 2007. Botryllus schlosseri: a model ascidian for the study of asexual reproduction. Dev. Dyn. 236: 335-352.

Mùgica, M., U. Izagirre, and I. Marigómez. 2015. Lysosomal responses to heat-shock of seasonal temperature extremes in Cd-exposed mussels. Aquat. Toxicol. 164: 99-107.

Puppel, K., A. Kapusta, and B. Kuczyńska. 2015. The etiology of oxidative stress in the various species of animals, a review. J. Sci. Food Agric. 95: 2179-2184.

Rzhetsky, A., and M. Nei. 1992. Statistical properties of the ordinary least-squares, generalized least squares, and minimum-evolution methods of phylogenetic inference. J. Mol. Evol. 35: 367-375.

Saitou, N., and M. Nei. 1987. The neighbor-joining method: a new method for reconstructing phylogenetic trees. Mol. Biol. Evol. 4: 406-425.

Sneath, A., and R. Sokal. 1973. Numerical Taxonomy: the Principles and Practice of Numerical Classification. Freeman, San Francisco, CA.

Snedecor, G. W., and W. G. Cochran. 1980. Statistical Methods, 7th ed. Iowa State University Press, Ames.

Sourdis, J., and M. Nei. 1988. Relative efficiencies of the maximum parsimony and distance-matrix methods in obtaining the correct phylogenetic tree. Mol. Biol. Evol. 5: 298-311.

Sunde, R. A., and W. G. Hoekstra. 1980. Structure, synthesis and function of glutathione peroxidase. Nutr. Rev. 38: 265-273.

Tamura, K., G. Stecher, D. Peterson, A. Filipski, and S. Kumar. 2013. MEGA6: Molecular Evolutionary Genetics analysis Version 6.0. Mol. Biol. Evol. 30: 2725-2729.

Tang, X., Y. Nakata, H. O. Li, M. Zhang, H. Gao, A. Fujita, O. Sakatsume, T. Ohta, and K. Yokoyama. 1994. The optimization of preparations of competent cells for transformation of E. coli. Nucleic Acids Res. 22: 2857-2858.

Tomanek, L. 2014. Proteomics to study adaptations in marine organisms to environmental stress. J. Proteomics 105: 92-106.

Toppo, S., S. Vanin, V. Bosello, and S. C. Tosatto. 2008. Evolutionary and structural insights into the multifaceted glutathione peroxidase (Gpx) superfamily. Antioxid. Redox Signal. 10: 1501-1514.

Voskoboynik, A., N. F. Neff, D. Sahoo, A. M. Newman, D. Pushkarev, W. Koh, B. Passarelli, H. C. Fan, G. L. Mantalas, K. J. Palmeri et al. 2013. The genome sequence of the colonial chordate, Botryllus schlosseri. Elife 2: e00569.

Zeeshan, H. M., G. H. Lee, H. R. Kim, and H. J. Chae. 2016. Endoplasmic reticulum stress and associated ROS. Int. J. Mol. Sci. 17: 327. 


\section{A: Amino acid alignment of gclm sequences obtained by CLUSTAL W}

Rattus norvegicus Mus musculus Bos taurus Homo sapiens Gallus gallus Xenopus tropicalis Xenopus laevis Rana catesbeiana Danio rerio Salmo salar Branchiostoma belcheri Botryllus schlosseri Brugia malayi Loa loa Ascaris suum

Rattus norvegicus Mus musculus

Bos taurus

Homo sapiens Gallus gallus Xenopus tropicalis Xenopus laevis Rana catesbeiana Danio rerio Salmo salar Branchiostoma belcheri Botryllus schlosser Brugia malayi Loa loa Ascaris suum

Rattus norvegicus Mus musculus Bos taurus Homo sapiens Gallus gallus Xenopus tropicalis Xenopus laevis Rana catesbeiana Danio rerio Salmo salar Branchiostoma belcheri Botryllus schlosseri Brugia malayi Loa loa Ascaris suum

Rattus norvegicus Mus musculus Bos taurus Homo sapiens Gallus gallus Xenopus tropicalis Xenopus laevis Rana catesbeiana Danio rerio Salmo salar Branchiostoma belcheri Botryllus schlosseri Brugia malayi Loa loa Ascaris suum

Rattus norvegicus Mus musculus Bos taurus Homo sapiens Gallus gallus Xenopus tropicalis Xenopus laevis Rana catesbeiana Danio rerio Salmo salar Branchiostoma belcheri Botryllus schlosseri Brugia malayi Loa loa Ascaris suum
----MGTDSRAAGALLARASTLHLOTGNLLNWGRLRKKCPSTHSEELRDCIOKTLNEWSS 56 ----MGTDSRAAGALLARASTLHLQTGNLLNWGRLRKKCPSTHSEELRDCIQKTLNEWSS 56 ----MGTDSRAAGALLARASTLHLQTGNLLNWGRLRKKCPSTHSEELRDCIQKTLNEWSS 56 ----MGTDSRAAKALLARARTLHLQTGNLLNWGRLRKKCPSTHSEELHDCIQKTLNEWSS 56 ----MGTEG--ARALLERARTLNLQTGNLLSWGCGRKKCPVTPSEEVRDCIQKTLTEWSS 54 ----MGTDSTAARTLLDKADKLVIOTGNLLNWGCLKKKCPSTPSEELODCIRTTLNEWSQ 56 ----MGTDSTAARTLLDKADTLILQTGNLLNWGCLKKKCPTTPSEELQDCIRTTLNEWNQ 56 ----MGTDT--ARSLLSAARTLILHTGNLMNWGRLKKKCPVTPGEELGDCIRITLSEWSS 54 ----MEHHVN-AKRLFSHATTLKLHTGNLVNRSRLKKKCPSSPSEELQDCIQGTLSEWFT 55 ----METHTTGAKVLLNHATTLNLHTGNLVNRSRLKKKCPSSPSEEIQDCVRATLSEWFA 56 --MSAVPVEEIARLMLSSTNNLTLHTGNI INWNHLKRKTSONAGEEVLECLSATLNVWSS 58 ------MDXAQMXVDQADTVVIXSGNI INSYSLKKRVGQKSSDELADS IEKTFTSWKE 52 MSTKVNHSSME I ISQVQKS SAVRLNTGNIQRHPELFRQMFRNSAEELVAALEHQL----D 56 MSTKVSQSSVEIMSQVQKSSAVCLNTGNIQRHPELFRQLFKNSAEELVAALEHQL----D 56 MESKAYNK-----SELR---VFRLNTGNINSCGELKRRACKDSAEELVAALQIEL----N 48

QIS-PDLVREF-PDVLECTMSHAVEKINPDEREEMKVSAKLFIVGSNSSSSTRNAVDMAC 114 QIS-PDLVREF-PDVLECTMSHAVEKINPDEREEMKVSAKLFIVGSNSSSSTRSAVDMAC 114 QIS-PDLIREF-PDVLECTVSHAVEKINPDEREEMKVSAKLFIVGSNSSSSTRNAVDMAC 114 QIN-PDLVREF-PDVLECTVSHAVEKINPDEREEMKVSAKLFIVESNSSSSTRSAVDMAC 114 KVG-RDQNQEM-VEVLECTVAQAVEKMNPEERDELKVSAKLFIVGSNSSS-IRDAVDMAC 111 KFS-PELVKEI-PQTLECTVPQAMETINLDEREEMKVSVKLFIVSPSHSS-VTQAIDMAC 113 KIS-PELVKDI-SQTLECTVSQAMETINLDEREEMKVSVKLFIVSPSLSS-VTEAIDMAC 113 KAS-PEHIODS-SOTLECAVNOALETINPEEREVMKVSAKLFVLDSGLSS-IGHAVDMAC 111 AMP-SSIDSEL-PSVLDCSIPENTEAITPEEREELKVSVKLFLTEWDCSS-IRSAVDMAC 112 TIPPPTSPTDL-PDTIDCSIPQATEAITPEEREELKVSVKLFICEADLSS-IKDAVDKAC 114 TVDPSWMNEES-NNALI ITNPNQMERISEDERSKLKVSVKIFLLKWDPDL-VVEAVDQVC 116 SVGPEYMNI PEPI HTLNVTNDALTWSHTDEIRSDLKISAKIFLSEVEPQL-VRNAVXNVC 111 GPNGPDLEMRP-DGTIMLTRDSENCRLNT IEKNDMKITLKVFMSSLDIKO-VEESIDTAL 114 GPNGPDLAMRP-DGTVMLARDSENCRLNTIEKADMKITLKVFMSSLDIKQ-VEESIDTAL 114 KRD--DLHFAN-DQTISLAAMET----NNYPRNDLKITLKVFMSSSDFSQ-VTDCLNATK 100

$$
.: \quad: \quad \quad: \quad:{ }^{\star}:{ }^{\star}{ }^{\star}{ }^{\star} \text {. } \quad . \quad .:: \text {. }
$$

SVLGVAOLDSVIMASPPIEDGV---------NLSLEHLQPYWEELENLVQSKKIVAIGTS 165 SVLGVAQLDSVIMASPPIEDGV--------NLSLEHLQPYWEELENLVQSKKIVAIGTS 165 SVLGVAQLDSVIIASP PVEDGV---------NLSLEHLQPYWEELQNLVQSKKIVAIGTS 165 SVLGVAQLDSVIIASPPIEDGV--------NLSLEHLQPYWEELENLVQSKKIVAIGTS 165 SSLGVAQLDSVIIAPSAIEDET---------SLSLEYLQPYWQELETLVENKKIVAIGTS 162 STLGVAOIDSMIIAPPPLEDGR---------SFSLEDLOPYWEELESLVRNGKVVSIGTS 164 STLGVAQIDSVIIAPPPLEDGR---------SVSLENLQPYWEELERLVRDAKVVSIGTS 164 STLAVGQLDSVIIAPP PLEDGV---------ILTLEHLQPYWRELESLVQDNKVVAIGTS 162 LSLGVSQLDSVFIAPP PLPEGE--------AQTLTHLQPLWQELESLVQSQKIAAIGTS 163 QALAVSQLDSVIIAPPALPEEE---------SQTLANLQPAWRELEGLVQSHKIATIGTS 165 NELDIGVVDSVLLALPPIEAEMG-------EELTVNHI I PMWEPMERLYDVERVSAIGTS 169 KTLGVXYLDSAVVXFPXXXPEAY-------VEGSFSKALSVWREMEAMTKEGLVKHIGVT 164 HEINTKS ISQLI IAFP PDDKLDIDPSVPTEVEEWLSH ILPFWTQLETLVRTHKINTLGVA 174 REINTKSISQLIIAFP PDDKLDIDLSVPSEVQRWLSHILPFWKQLETLVRTHKVNTLGVA 174 SLLGVESIEQLIMSFN-NFEPESEDSEDKELKNWVENVISVWEKIEALVKNGEISTVGVA 159

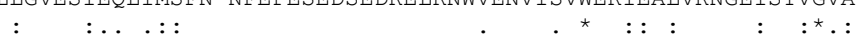

DLDKTQLEQLYQW-AQVKPNSNQVNLASCCVMPPDLTAFAKQFDIQLLTHNDPKELLSEA 224 DLDKTOLEOLYOW-AOVKPNSNOVNLASCCVMPPDLTAFAKOFDIOLLTHNDPKELLSEA 224 DLDKTOLEOLYOW-AOVKPNSNOVNLASCCVMPPDLTAFAKOFDIOLLTHNDPKELLSEA 224 DLDKTQLEQLYQW-AQVKPNSNQVNLASCCVMPPDLTAFAKQFDIQLLTHNDPKELLSEA 224 DLDKTLLEQLYVW-AQVKPSSNQVNLASCCVMPPDLTAFAKQFDIQLLTHNDPKELLCEA 221 DLDKALLEQLYLW-SQVKPASNQVNLASCCIMPPDLTEFAKQFDIQLLTHNDPKELLSEE 223 DLDKALLEQLYLW-SQVKPASNQVNLASCCIMPPDLTEFAKQFDIQLLTHNDPKELLSEE 223 DLDKPLIEOLYLW-AOIKPSSNQVNLASCCIMPPDLTAFAKEFDIOLLTHSDSKEILSEE 221 DLDKTLLEQLYNW-AQIKPSSNQVNLASCCVMPPDLTAFAKEFDIQLLTHSDPKELISAA 222 DLDKELLEQLYNW-AQVKPSSNQVNLASCCVMPPDLTAFAKEFDIQLLTHNDPKELITAA 224 DLDKEMLEQTHGM-ARVKPT INQVNVVSCCVIPPELTAFAKENDIQLLTHSDPRDVLPTP 228 DFDKTAMQNLYRC-ATVKPTIDQIKTGHDFNVPDDLIKLSEEYDIELLSHDDAADMLPEK 223 DLDYEOLKALYESTNDHRPMIDHYSTEHCCTVPPELREYAKOKDIOLLTHNDPNLHSINE 233 DLDYEQLKALYESTDDHRPMIDHYSTEHCCTVPPELREYAKQKDIQLLTHNDPN-LYSIS 233 DFDLNHLKALYDG-AEIKPRIAHFNIAGCCSVPKDLQDYARENDIQLLTHNDPK-PFVTA 217

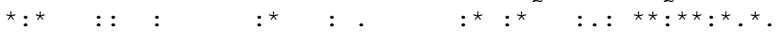

SFOEALQESIP-DIEAQEWVPLWLLRYSVIVKSRGIIKSKGYILQAKRKGS--------- 274 SFQEALQESIP-DIEAQDWVPLWLLRYSVIVKSRGIIKSKGYILQAKRRGS--------- 274 SFQEALQES I P-DIRAHEWVPLWLLRYSVIVKSRGIIKSKGYILQAKRKGS--------- 274 SFQEALQESIP-DIQAHEWVPLWLLRYSVIVKSRGIIKSKGYILQAKRRGS--------- 274 SFOEVLOESIO-NVKAHEWI PLWILRYSVIVKSRGIIKSKGYIMOAKRNAS---_---- 271 AFOEALKESAO-ECHSSAWSPIWILRYSVIVKTRGIIKLKGYILQAORKGSL-------- 274 DFQEALKESVP-ECHFNAWSPIWILKYSVIVKTRGIIKLKGYILQAKRKGSF-------- 274 SFQEVLRDSVE-GSDADEWS PVWVLRYSVIVKTRGIIKSKGYIVQAKRKAPH-------- 272 GFQEAVQGSSQ-ELQVDDWRLEWVLRYSI IVKSRGI IKAKGY IVHAKKSNNH-------- 273 SFQEAVQESTQ-DLKVADWRLEWVLRYSI IVKSRGIIKAKGYLVHAKRSSL-------- 274 TFOEILRGSSH-DDHVDEWOPFWVLRYTVMVKCRGVIKAKGYIVNGRRHATDMPLSVA-- 285 SFQA IMEDNFPNSTSASEWLPSYAVRYSAIARCRGIVRSKGYIVEAGKRLSNGYYTVTTG 283 ERLDATT---RKLFGNEHFDLLFIARLTVWLRSRS I IVGKGY I LKFMRKIS--------- 281 ERLDATT---RKLFGNEHFELLFIARLTVWLRSRS I IVGKGY ILKFLRKI--------- 280 DGLKDICNNEKYPLCDHDYKPSWASRYTVWVRGRS I IAAKGYMVQFERS----------- 266 
Rattus norvegicus

Mus musculus

Bos taurus

Homo sapiens

Gallus gallus

Xenopus tropicalis

Xenopus laevis

Rana catesbeiana

Danio rerio

Salmo salar

Branchiostoma belcheri

Botryllus

Brugia malayi

Loa loa

Ascaris suum 


\section{B: Amino acid alignment of gs sequences obtained by CLUSTAL W. Green highlight active sites, pink highlight ATP binding sites, yellow highlight magnesium binding sites and red highlight GSH binding sites. Grey highlight amino acid with catalytic and ATP binding activity.}

Homo sapiens

Macaca fascicularis Callithrix jacchus Bos taurus

Rattus norvegicus

Xenopus laevis

Xenopus tropicalis

Danio rerio

Branchiostoma floridae

Botryllus schlosseri

Brugia malayi

Loa loa

Ascaris suum

Homo sapiens

Macaca fascicularis

Callithrix jacchus

Bos taurus

Rattus norvegicus

Xenopus laevis

Xenopus tropicalis

Danio rerio

Branchiostoma floridae

Botryllus schlosseri

Brugia malayi

Loa loa

Ascaris suum

Homo sapiens

Macaca fascicularis

Callithrix jacchus

Bos taurus

Rattus norvegicus

Xenopus laevis

Xenopus tropicalis

Danio rerio

Branchiostoma floridae

Botryllus schlosseri

Brugia malayi

Loa loa

Ascaris suum

Homo sapiens

Macaca fascicularis

Callithrix jacchus

Bos taurus

Rattus norvegicus

Xenopus laevis

Xenopus tropicalis

Danio rerio

Branchiostoma floridae

Botryllus schlosseri

Brugia malayi

Loa loa

Ascaris suum

Homo sapiens

Macaca fascicularis

Callithrix jacchus

Bos taurus

Rattus norvegicus

Xenopus laevis

Xenopus tropicalis

Danio rerio

Branchiostoma floridae

Botryllus schlosseri

Brugia malayi

Loa loa

Ascaris suum

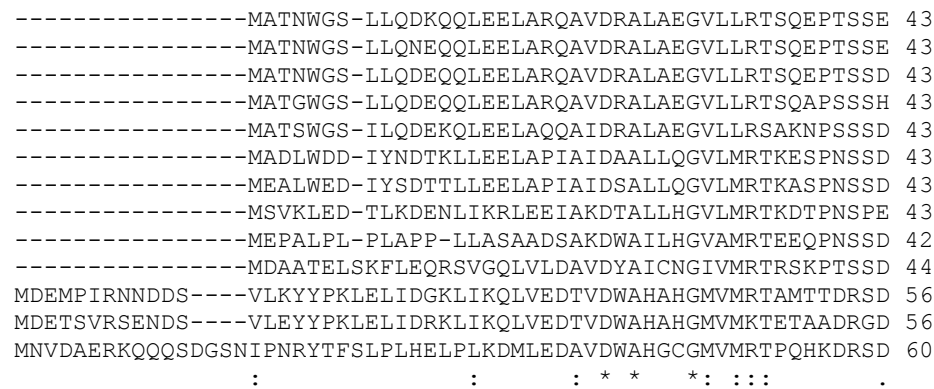

VVSYAPFTLFPSLVPSALLEQAYAVQMDFNLLVDAVSQNAAFLEQTLSSTIKQDDFTARL 103 VVSYAPFTLFPSLVPSALLEQAYAVQMDFNLLVDAVNQNAAFLEQTLSSTIEQDDFTARL 103 VVSYAPFTLFPSLVPSALLEQAYAVQMDFNMLVDAVSQNAAFLEQTLASTIKRDDFTARL 103 VVSYAPFTLFPSPVPSALLEOAYAVOADFNLLVDAVSONAVFLEOTLSSTIKRDSFTARL 103 VVTYAPFTLFPSPVPSTLLEQAYAVQMDFNILVDAVSQNSAFLEQTLSSTIKKDEYTARL 103 VVSFAPFALLPSPVPKALFEQAKCVQEDFNTLVDRISQDTSFLEQVLSSTIKVDDFIRRL 103 VVNFAPLTLLPS PVPKALFEQAKSVQEDFNLLVDRISQDTDFLEKALSSTAKVDDFIQRL 103 VVSYAPFTLFPTSVPAALFHQALAVQTQFNRLVDRVSQNHSFLEDTLASTIKVDDFTARL 103 VNFAPFLLLPSPVPRILFDQAKAVORDFNLLVHRLSODTNFLTSCLKSTIOVDDFTCRL 102 VVQHAPFTLLPS PVPKNLYEQA ISVQKDFNFLMHAISQDPEFMKSAFSTIIHSDDFTRRL 104 ICQTAPCTLFPSPFPYNLFQEAMDIQRTFSLLYFRISWDFDFLIKSHAEVVKTDDFTRHF 116 ICQIAPCTLFPSPFPYSLFQEAMDIQQAFSLLYFRISWDFDFLIKSHAEVVKTDDFTKHF 116 ICQTAPFTLLPSPFPRHIFQQAVDVQQATNLLYFRMSWDYEFLIESHAEVVKTDDFTRHF 120

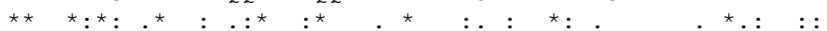

FDIHKQVLKEGIAQTVFLGL FDIHKQVLKEGIAQTVFLGLN

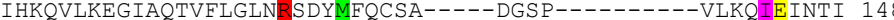
FDIHKQVLKEGIAQTVFLGLNRSDYMFQCNP-----DGSA---------ALKOIEINTV 148 FDIYKQVLKEGIAQTVFLGLNRSDYMFQCSA-----DGSK---------ALKQIEINTI 148 FAIHKQVQQEDCTQEVFLGINRSDYMFDCRD-----DGTP----------ALKQIEINTI 148 LKIQRQVKKEGCEQEVFLGINRSDYMFDCRD-----DGTP----------ALKQIEINTI 148 FNIYKQVQQEGHAQKIVVGLNRSDYMLDHSP-----DGRT----------SLKQIEINTI 148 FRIYEOVRREGVAQTVCLGLHRSDYMLDDPSRTGQENGEPEAKQPRLDLLQLKQIEINCI 162 FEIYETALLE-KPKKTAMA I IRSDYMFNKTD-----ESEP---------SLKQIEVNMI 148 VEILNAVXTSNFCQKKTLLIQRNDYMCHEDS-----YGNR----------SLKQIEVNNI 161 VEILNAVRTSDFCQRKTLMIQRNDYMCHEDN-----YGNR----------SLKQIEVNNI 161 VDILKRVHEAGIKQTKTLLIQRADYMCDGQR-----SDEF----------KLKQVEVNNI 165

$$
\star \star \star *{ }^{\star}:{ }^{\star}:
$$

ASFGGLASR-TPAVHRHVLSVLSKT--KEAGKILSNNPSKGLALGIAKAWELYGSPNAL 205 SFGGLASR-TPAVHRHVLSVLSKT--KEAGKI LSNNPSKGLALGIAKAWELYGSTNAL 205 SFGGLASR-TPAVHRHVLSVLSKT--KEAAKILSNNPSKGLALGIAKAWELYGSANAL 205 SFGGLASR-TPAVHRHVLSVLGKT--KEAAKILSNNPSKGLAMGIAKAWELYGSANAQ 205 SFGGLASR-TPAVHRHVLNVLNKT--NEASKILSNNPSKGLALGIAKAWELYGSANAV 205 SFGGLASR-TPAVHQHVLKFLRKS--EESSSILTNDAVEGIGWGIAHAWALYGSVDAT 205 SFGGLSAR-VPEVHQHVLKVLKKS--EEASNI LPNNPVEGIAWGIASSWAVYGSTSAV 205 SFGGLASR-TPDVHRHILKVANLP--DECSLVLDNNPAAGLAKGLAKAWELYGSKRAV 205 SFGGLGTQ-MPGLHRHVLRLCGVSRFTADQQLPQNRAMSSLADGLAAAWELYGEQSAV 221 SFGGIGTEKTRSLHDYTLRHAGFE--DVATSLPQNKALQNLAQS IVNAWDLYGDNSAV 206 SMGXLAER-ATCVHKRTLETVQLPSKIIEKAIXDNHPTVTIARGIYEAWYDFGVPEAI 220 SMGSLAER-ATCVHRRTLETLQLPNKI IEKAI LNNHPTVTVAKGICEAWYDYGVPEAI 220 SMGWLSEM-ASCLHRRVLQDLNVPDDI IANALPENRPIDTVAKGIYDAWLDIGDQSAL 224

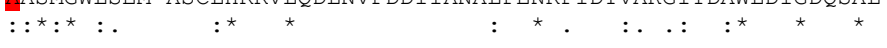

VLLIAQEKERNIFDQRAIENELLARN---IHVIRRTFEDISEKGSLD--QDRRLFVDGQE 260 VLLIAQEKERNIFDQRAIENELLARN---IHVIRRTFEDISEKGSLD--QDRRLFVDGQE 260 VLLIAQEKERDIFDQRAIENELLARN---IHVIRRRFEAISEKGSLD--QDRRLFVDGQE 260 VLLIAQEKERNIFDORAIENELLARN---IHVIRRRFEDVSEKGSLD--QDRRLFMDGQE 260 VLLIAQEKERNIFDORAIENELLDRK---IHVIRRRFEDVSERGSLD--QNRRLFMEDQE 260 VMFLVENE RNILDORFIEAELCKRN---VRVIRRRLADVFERGTLD--EERHLFIDGYE 260 VLFLVENV RN I LD RCIENELMKRN---VRTIRRRLADVYERGSLD--KDRGLFLDGYE 260 VLFLVENVORNIYDHRYVENELWKRN---IPVIRROFEDVFRTGSLD--ESKRLFVDGHE 260 IVFVVQEENRNAMD HWLEFAAMDRNP-SIRVRRYTLTQI HDRGELR--PDKTLLVDGEE 278 IVFVITDIENNIFDQRALEFRICEIQP-DIVVKRYTLTQISELGDHD--DDGNMVINDQK 263 VLFVVEDANRNQID RHVEYCIDELSNRNARCLRITLTDGAKRLKLN-ESNHHLVLDNIL 279 ILFVVEDANQNQI DORHVEYCIDELSSRS IRCLRITLTDGAKRLKVN-ETNHYLVLDNML 279 ILFVVEEVNQNQVDQRHVEYRIDELSSRRAKCVRLTLTQCAERLSLGGRSGHDLMLDACR 284 
Homo sapiens

Macaca fascicularis

Callithrix jacchus

Bos taurus

Rattus norvegicus

Xenopus laevis

Xenopus tropicalis

Danio rerio

Branchiostoma floridae

Botryllus schlosseri

Brugia malayi

Loa loa

Ascaris suum

Homo sapiens

Macaca fascicularis

Callithrix jacchus

Bos taurus

Rattus norvegicus

Xenopus laevis

Xenopus tropicalis

Danio rerio

Branchiostoma floridae

Botryllus schlosseri

Brugia malayi

Loa loa

Ascaris suum

Homo sapiens

Macaca fascicularis

Callithrix jacchus

Bos taurus

Rattus norvegicus

Xenopus laevis

Xenopus tropicalis

Danio rerio

Branchiostoma floridae

Botryllus schlosseri

Brugia malayi

Loa loa

Ascaris suum

Homo sapiens

Macaca fascicularis

Callithrix jacchus

Bos taurus

Rattus norvegicus

Xenopus laevis

Xenopus tropicalis

Danio rerio

Branchiostoma floridae

Botryllus schlosseri

Brugia malayi

Loa loa

Ascaris suum

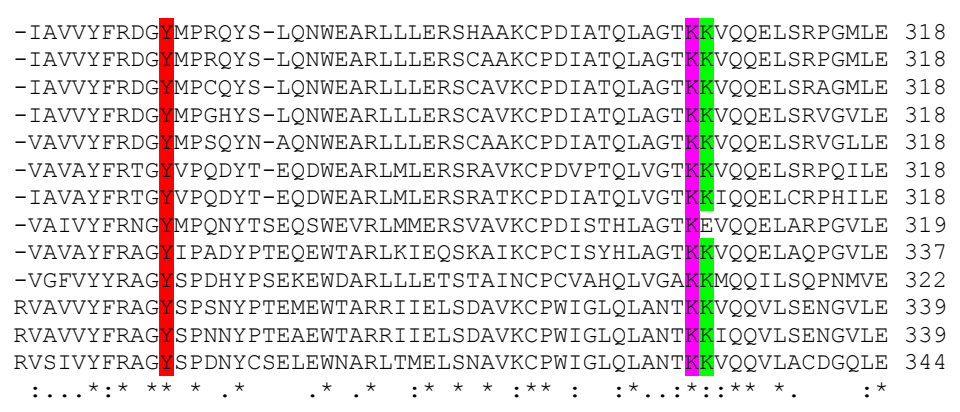

MLLPGQPEAVARLRATFAGLYSLDVGEE-GDOAIAEALAAPSRFVLKPOREGGGNNLYGE 377 MLLPGQPEAVARLRATFAGLYSLDMGEE-GDQAIAKALAAPSRFVLKPQREGGGNNLYGE 377 MLLPGQPEAVARLRATFAGLYSLNMGEE-GDQAIAEALAAPSRFVLKPQREGGGNNLYGE 377 SFLPGQPEAVARLRATFAGLYSLDLGEE-GDQAITKAIAAPSCFVLKPQREGGGNNLYGE 377 ALLPGQPEAVARLRATFAGLYSLDMGEE-GDQAVAEALAAPSHFVLKPQREGGGNNFYGE 377 KFLPDKPEAVARIRETFTGLYSLDIGEE-GDEAVRVALANPDQFVLKPQREGGGNNLYGE 377 KFLPDNPEAVARIRETFAGLYSLDTGEE-GDEAVKAALANPDOFVLKPOREGGGNNLYGE 377 CFFPDEPETVSQIRATFAGLYTLDMGEE-GDNTVAMALANPDQYVLKPQREGGGNNIYGS 378 KFLKD-AEAVKRVRATFAGQYTLELGAE-GDRTVQMVTSDPGRFVMKPQREGGGNNIFGE 395 RFIKD-RNSVKRIRDTFVGFYGLEMGST-GDESIQKVLQHPENYVLKPQLEGGGNNLYND 380 KYITDDKM-CARIRQTFAGMWGLENDDEKTQRIIQDAIAHPEKFVLKPQLEGGGGNYYGK 398 RYITDGRM-STRIRKTFAGMWGLENDDDRTQKIIQDAVTHPEKFVLKPQLEGGGGNYYGK 398 RFLPELKEDCERIRATFAGLWGLESDEEETQIILKEAIEYPERFVLKPQLEGGGGNYYGS 404

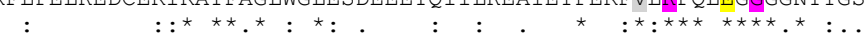

EMVOALKOLKDSEERASYILMEKIEPEPFENCLLRPGSPARVVOCISELGIFGVYVRO-- 435 EMVQALKQLKDSEERASY ILMEKTEPEPFENCLLRPGSPAQVVQCISELGIFGVYVRH-- 435 EMVQALKQLKDSEERASY ILMEKIEPEPFENCLLRPGSPVQVVQCISELGIFGVYVRQ-- 435 EMVQALERLKDSEERASY ILMEKIEPEPFRNCLLRPGSPARVIQCISELGIFGVYVRE-- 435 EMVHALEQLKDSEERASYILMEKIEPEPERNCLLRPGSPAQVVQCISELGIFGVYVRQ-- 435 ELKEKLQECKDSEERTSY I LMDKINPKPLKNCLLRAGGRVQISECISELGMFGVYVRH-- 435 ELKAKLEECKDSEERNSY ILMDKINPKTTKNCLLRAGGPVQISECISELGMFGVYVRR-- 435 EICEVLEKLKNSSERTAYILMDKIQPVPVQNILLRPGAPLKVSSCLSELGAFGAYVRK-- 436 DIPAALNNMADVKERTAY IVMDRIRPAVVSNYAVRPGREPALTEAVSELGIFGVFIGK-- 453 EMVAKLKEVGEDDRRCSY IVMEKY----------------VRCQCSLSSYGPKQAT-- 420 EVAEKLKTMNR-DEMAAYIIMERITPMVVKNYVIRPQEEPLLMDVVGELGVYAYLYGSAA 457 EVAEKLKTMSR-DEMAAYI IMERITPMVVKNYVIRPRQEPVLMDVVGELGIYAYLYGSPA 457 EVAEKLKEMSR-DERAAHI LMERIQPMRVKNYLVRPFEEVTLGEVVGELGIYGCLYAEPG 463 $: \quad{ }^{*}:$ . : : : $:{ }^{\star}:$ : $\cdot{ }^{\star} \cdot$ : .

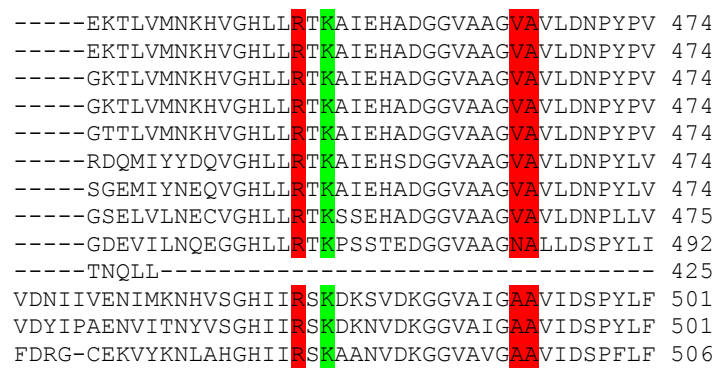




\section{C: Amino acid alignment of GPx 5 sequences obtained by CLUSTAL W. Red residue correspond to selenocystein and green residues are amino acids with catalytic activity.}

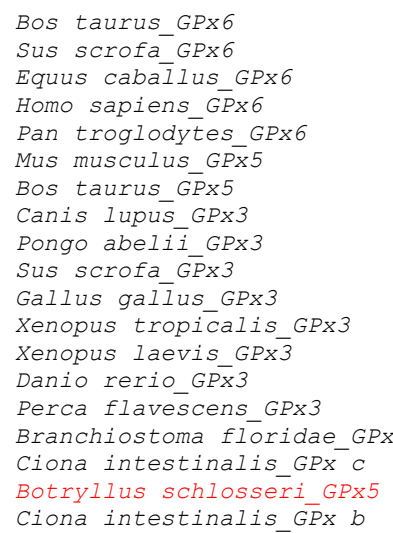

MILQLWASCLFPLFLVGLAQLTPKQQQMKVDCYKGVTGTIYEYGALTLNGEEYIQFKQYV 60 MTPQFWASCLFSLCLVGFAQLIPKEQKMKMDCYKGVTGTIYEYGALTLNGEEYIPFKQYA 60 MIRQLWASSLFPLFLVGFAQLTPESQKMKMDCYKGVTGTIYEYGALTLNGEEYIQFKQYA 60 MFOOFOASCLVLLFLVGFAOOTLKPONRKVDCNKGVTGTIYEYGALTLNGEEYIOFKOFA 60 MFROFOASCLVLLFLVGFAOOILKPONRKVDCNKGVTGTIYEYGALTLNGEEYIOFKOFA 60 MVTELRVFYLVPLLLASYVQTTPRPEKMKMDCYKDVKGTIYDYEALS LNGKEHIPFKQYA 60 MTIQLRASCLFLFFLAGFVQTNSNLE--KMDCYKDVKGT IYDYDAFTLNGKEHIQFKQYA 58 MARLLRASCLLSLLLAGFVPPSRGQEKSKTDCHGGVSGTIYEYGALT INGEEYIPFKQYA 60 MARLLOASCLLSLLLAGFVPOSRGOEKSKMDCHGGISGTIYEYGALTIDGEEYIPFKOYA 60 MARFFRASCLISLLLAGFLPPSRGQEKSKTDCYRGVSGT IYEYGALTIDGEEYIPFKKYA 60 --MGCRAACVLAVLLAGLVPLGQGQEREKVKCYDSVRGTIYDYGALTIDGDEYIPFRKYA 58 MGVKLRGLLMLPCFLAALIHAQNEMDQKSVDCYSSIDGTIYDYGATTLDGTQFIPFKAYQ 60 MGVKFRGLLMLPCI LAAF IHAQTDVDQKSVDCYSSADGS IYDYGATTLDGSQFIPFKAYQ 60 MGTQSNPWTSVVLLLA--LMHKIAALSNTQACNSAAGDSFHNYGAKT INGTQFIPFSHYA 58 MNGPAHHGHGRLSHSKLHHAAPHPIELNTPLCPASVVGSFFELSAEALGG-EMIPFSTYD 59 -----MHQKGAVPAVLLVLGTLAVATS IENSTCFHNTFSVYDHSFPTLSG-ETVNLGEFR 54 -------MLWALLVASAALVAADDASQCLSQGLTGTVYDSTEATLAG-TNVDLTQLF 49 --------MRSAVLLWLGVAGVVHSMVPCYNSTN-YSVYSNQVFNLHK-QNVNLSRFH 48
GKHVLFVNVATYUG-LTAQYPELNALQEELKPFGVVVLGFPCNQFGKQEPAKNSEILMGL 119 GKHVLFVNVATY GKHVI TVUATY G-LTAQYPELNATOETKPFGVVILGFPCN GKHVLFVNVATYUG-LAAQYPELNALQEELKNFGVIVLAFPCNQFGKQEPGTNSEILLGL 119 GKHVLFVNVATYCG-LTIQYPELNALQEDLKPFGLVILGFPCNQFGKQEPGDNLEILPGL 119 GKHVLFVNVATYCG-LTAQYPELNALQEELKPFGLVVLGFPCNQFGNQEPGENSEILPGL 117 GKY ILFVNVASYUG-LTGOYLELNALOEELAPFGLVILGFPCNOFGKOEPGENSEILPSL 119 GKYVLFVNVASYUG-LTGQYIELNALQEELAPFGLVILGFPCNQFGKQEPGENSEILPTL 119 GKYVLFVNVASYUG-LTGQYVELNALQEEFEPFGLVILGFPCNQFGKQEPGDNSEILSTL 119 GKMVLFVNVATYUG-LTLQYLELNALQNELGPYGLVVLGFPSNQFGKQEPGQNSEILPAL 117 GKYILFVNVATYUG-LTMQYQELNALQEELKNNNFVILGFPSNQFGMQEPGRNDEILLGL 119 GKYLLFVNVATFUG-LTMQYQEMNALHEELKSNDFVILGFPCNOFGLQEPGRNDEIPLGL 119 GKHVLVVNVATYUG-LTFQYVELNALHEELRHLGFTILGFPCDQFGKQEPGENNEILSAL 117 -------------------------MKPLGLTLLGFPCNQFGKQEPGTNHEILPGL 31 GKVVLVVNVASASEHTTREYLQLNDLVATYGPKGLIVLGFCCNQFGNGEPFSNHEILRCL 119 GNVSMVINVATYUGATVPQYKAMNALSEEYTQSSFVTLAFPCNQFGLQQPEANDEILNGV 114 GYVSVVMNPGVYSEWTSOMMTGMNTLLEKYESDGVVGLGFPCNOFNLEQPGSPGEILNAY 109 NEVTLLINVATYUGLTVAQYTGLALLTHFNGRNFSVLAFPCDQFHLEEPGEDSEILNGL 108

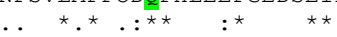

KYVRPGGGFVPN--FQLFEKGDVNGEKEOKVFTFLKNACPPTSD---LIGSSS-OLFWEP 173 KYVRPGGGFVPN--FQLFEKGDVNGEKEQKVFTFLKNSCPPTSD---LLGSSN-QLFWEP 173 KYVRPGGGFVPN--FQLFEKGDVNGEKEQKVFTELKNSCPPTSD---LLGSPK-QLFWEP 173 KYVCPGSGFVPS--FQLFEKGDVNGEKEQKVFTFLKNSCPPTSD---LLGSSS-QLFWEP 173 KYVCPGSGFVPS--FQLFEKGDVNGEKEQKVFTFLKNSCPPTSD---LLGSSS-QLFWEP 173 KYVRPGKGFLPN--FOLFAKGDVNGENEOKIFTFLKRSCPHPSE---TVVMSK-HTFWEP 173 KYVRPGGGYVPN--FQLFKKGDVNGETEQKVFTFLKQSCPHPS---_-_-_-----WEP 161 KYVRPGGGFVPN--FQLFEKGDVNGEKEQKFYTFLKNSCPPTSE---LLGSPG-RLFWEP 173 KYVRPGGGFVPN--FQLFEKGDVNGEKEQKFYTFLKNSCPPTSE---LLGTSD-RLFWEP 173 RYVRPGGGFIPN--FQLFEKGDVNGEKEQKFYTFLKNACPPTSE---LLGSPS-RLFWEP 173 KYVRPGGGFVPN--FOLFOKGDVNGAKEOKVYSFLKNSCPPVAE---EFGNPK-NLFWEP 171 EYVRPGGKFVPN--FQLFEKGDINGRKEQKFYTFLKNSCPPVGD---NFGSATNRLMWEP 174 RYVRPGGNFIPN--FQLFEKGDVNGRKEQKFYTFLKNSCPPVGD---TFGNPAFRLNWEP 174 KYVRPGNGFVPN--FQLFEKGDVNGDGEQALFTFLKNACPPVGE---SFGATSNRLFWEP 172 KHVRPGNGFVPN--FLLFEKGDVNGKDEQEVFTFLKNSCPPVGD---VLGNPT-RMFWDP 85 RAVRPGNRYSPN--FOLFSKVDINGKHGHIVFEYLKLKLPFPSDNAATMAOEHLDICWSP 177 MYVRPGHGFVPNKKIYFFSKTOVNGGSEDPLFTSIKASCPPTTN---NIGITS-ELYWTP 170 KYLRPGNGWTPHQNFHLFTVTEVNGDTASDIFKFLRSACPAYTE---ELGSKA-SFYWDT 165 MYVRPGNGYVPHPKLNIFGKIKVNGRHEHTIYKNVKASCPPTTL---NLGSTR-NMYWNP 164

$$
: \star \star \quad: * \quad: \quad:{ }^{*}: \star \star \quad .: \quad:: \quad * \quad *
$$

MKVHDIRWNFEKFLVGPDGVPVMRWYHRASVSTVKSDMLEYLKQFKSE------------ 221 MKVHDIRWNFEKFLVGPDGVPVMRWYHRASVSTVKSDIMEYLKQFKSE----------- 221 MKVHDIRWNFEKFLVGPDGVPVMRWFHRASVSTVKSDILEYLKQFTPE----------- 221 MKVHDIRWNFEKFLVGPDGVPVMHWFHOAPVSTVKSDILEYLKOFNTH-_-_-_-_--- 221 MKVHDICWNFEKFLVGPDGVPVMRWFHOAPVSTVKSDILEYLKOFNTH-_-_-_-_-_-- 221 $\begin{array}{ll}M K V H D I C W N F E K F L V G P D G V P V M R W F H Q A P V S T V K S D I L E Y L K Q F N T H---------- & 221 \\ \text { IKVHDIRWNFEKFLVGPDGVPVMRWFHQAPVSTVKSDIMAYLSHFKTI----------- } 221\end{array}$ IMVRDIRWNFEKFLVGPDGI PVMRWFHRTPVSTVKTDILAYMKQFKTK------------ 209 MKVHDIRWNFEKFLVGPDGIPIMRWYHRTTVSTVKMDILAYMRRQAALAIKGK------- 226 MKVHDIRWNFEKFLVGPDGI P IMRWHHRTTVSNVKMDILSYMRRQAALGVKRK------- 226 MKVHDIRWNFEKFLVGPDGVPVMRWYHRTT INTVKLDILAYMRRRAALEAKRO--_---- 226 MKVHDIRWNFEKFLVGP DGVPVMRWYHRTT INTVKLDI LAYMRRRAALEAKRQ------- 226
LRNHDIKWNFEKFLVGTDGVPVMRWYHRANIATVKNDI IAYMRQQRGQ----------- 219 IKVNDVKWNFEKFLVGPDGRPVKRWLPRTPVAQVRREIMSYMKLQPGTQRLLMLGLEQK- 233 LRVNDI KWNFEKFLVGPDGRAVKRWHPRTSVAQVRREIVSY IKLQQGTQRLLMLGLEQK- 233 LKVNDI KWNFEKFLLDPDGRPVMRWFPRVNVSEVRADI LKYFHQLLQTAQ---------- 222 VKLSDIKWNFEKFLVGPDGKPVMRWHPSVNISVVQADIRKYLLQLYTQQIFN-------- 137 VRRTDVSGNFEKFLVASDGQPYRRYSWRTAPEDLCKDIEELLRKVTRTNREQGNTGAKND 237 IKANDIYWNWNKFLLDKNGMI RYRFGSAVTATQLKPWIDQLLNEK------------- 215 LVARDLRGTYEKFVIDKNGKPRYRFAPNVAMTEIYPYIDELLAETPIQPTQFPGVEAGN- 224 VKSTDITWNFNKFLLDKNGVPRYRISSDASPTSLIPYITTMLSE--------------- 208 
Bos taurus GPX 6

Sus scrofa GPX

Equus cabaIlus GPx6

Homo sapiens_GP $\overline{6} 6$

Pan troglodytes GPX 6

Mus musculus GPX5

Bos taurus GPX5

Canis lupus GPX3

Pongo abelīi_GPX3

Sus scrofa GPX3

Gallus gallus GPX3

Xenopus tropicalis GPX 3

Xenopus laevis GPX3

Danio rerio_GPX3

Perca flavescens_GPX3

Branchiostoma floridae GPX

Ciona intestinalis $G P x^{-} C$

Botryllus schlosseri GPX5

Ciona intestinalis_GPX $b$

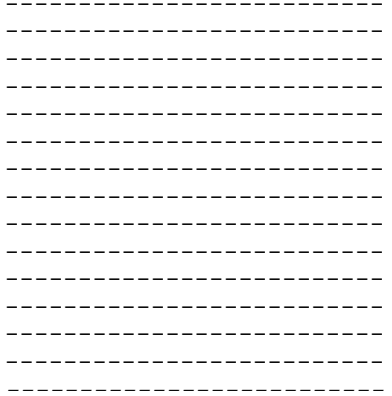

RPVLFNSKKYMQESITRSTVRDDAAY 263

--------------------------

- - - - - 


\section{D: Amino acid alignment of GPx3 sequences obtained by CLUSTAL W. Red residue correspond to selenocystein and green residues are amino acids with catalytic activity.}

Danio rerio GPX3

Perca flavescens_GPx3 Xenopus tropicalis GPX3 Xenopus laevis_GPX $\overline{3}$

Canis lupus GPX3

Pongo abeli $\bar{i}$ GPX3

Sus scrofa GPX3

Bos Taurus_GPX6

Sus scrofa GPx6

Equus cabāllus GPX6

Homo sapiens GPX6

Pan troglodytes_GPx6

Mus musculus_GPX5

Bos taurus GPX5

Gallus galīus GPX3

Branchiostoma floridae_GPX

Ciona intestinalis_GPX ${ }^{-} b$

Ciona intestinalis GPX $C$

Botryllus schlosseri GPx3

Danio rerio_GPX3

Perca flavescens GPX3

Xenopus tropicalis GPx3

Xenopus laevis GPX $\overline{3}$

Canis Iupus GPX3

Pongo abelīi_GPX3

Sus scrofa $\overline{G P} \times 3$

Bos taurus GPX

Sus scrofa GPx

Equus caballus_GPx6

Homo sapiens_GPX6

Pan troglodytes GPX6

Mus musculus GPX5

Bos taurus $\overline{G P} \times 5$

Gallus gallus_GPX3

Branchiostoma floridae GPX

Ciona intestinalis GPX $b$

Ciona intestinalis GPX $C$

Botryllus schlosseri_GPx3

Danio rerio GPx3

Perca flavescens GPx3

Xenopus tropicalis GPx3

Xenopus laevis GPx $\overline{3}$

Canis lupus GPX3

Pongo abelii GPx3

Sus scrofa $\mathrm{G} \overline{\mathrm{P}} \times 3$

Bos taurus_GPx6

Sus scrofa_GPx6

Equus cabalilus_GPx6

Homo sapiens GPx6

Pan troglodytes GPx

Mus musculus GPX 5

Bos taurus_G $\bar{P} \times 5$

Gallus galīus GPx3

Branchiostoma floridae GPx

Ciona intestinalis $\mathrm{GPx}^{-} \mathrm{b}$

Ciona intestinalis_GPx C

Botryllus schlosseri_GPx3

Danio rerio GPx3

Perca flavescens GPX3

Xenopus tropicalis_GPX3

Xenopus laevis_GPX $\overline{3}$

Canis lupus GPX3

Pongo abeli $\bar{i}$ GPX3

Sus scrofa GPX3

Bos taurus GPX6

Sus scrofa GPx6

Equus cabalilus GPX6

Homo sapiens GPX6

Pan troglodytes_GPx6

Mus musculus_GPX5

Bos taurus GPX5

Gallus gallus GPx3

Branchiostoma floridae_GPX

Ciona intestinalis_GPX b

Ciona intestinalis GPX C

Botrylius schlosseri GPX3
MGTQSNPWTSVVLLLA--LMHKIAALSNTQACNSAAGDSFHNYGAKTINGTQFIPFSHYA 58

MGVKLRGLLMLPCFLAALIHAQNEMDQKSVDCYSS IDGTIYDYGATTLDGTQFIPFKAYQ 60 MGVKFRGLLMLPCILAAFIHAQTDVDQKSVDCYSSADGS IYDYGATTLDGSQFIPFKAYQ 60 MARLLRASCLLSLLLAGFVPPSRGOEKSKTDCHGGVSGT IYEYGALT INGEEY I PFKOYA 60 MARLLQASCLLSLLLAGFVPQSRGQEKSKMDCHGG ISGTIYEYGALT IDGEEYIPFKQYA 60 MARFFRASCLISLLLAGFLPPSRGQEKSKTDCYRGVSGT IYEYGALTIDGEEYIPFKKYA 60 MILQLWASCLFPLFLVGLAQLTPKQQQMKVDCYKGVTGTIYEYGALTLNGEEYIQFKQYV 60

MTPQFWASCLFSLCLVGFAQLI PKEQKMKMDCYKGVTGTIYEYGALTLNGEEYIPFKQYA 60 MIROLWASSLFPLFLVGFAOLTPESOKMKMDCYKGVTGTIYEYGALTLNGEEYIOFKOYA 60 MFQQFQASCLVLLFLVGFAQQTLKPQNRKVDCNKGVTGTIYEYGALTLNGEEYIQFKQFA 60 MFRQFQASCLVLLFLVGFAQQILKPQNRKVDCNKGVTGTIYEYGALTLNGEEYIQFKQFA 60 MVTELRVFYLVPLLLASYVQTTPRPEKMKMDCYKDVKGTIYDYEALSLNGKEHIPFKQYA 60 MTIQLRASCLFLFFLAGFVQTNSNLE--KMDCYKDVKGTIYDYDAFTLNGKEHIQFKQYA 58 --MGCRAACVLAVLLAGLVPLGQGQEREKVKCYDSVRGTIYDYGALTIDGDEYIPFRKYA 58 MVTPNG

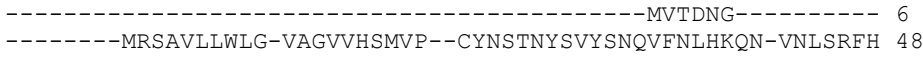
---MHQKGAVPAVLLVLG-TLAVATSIENSTCFHNT-FSVYDHSFPTLSGET-VNLGEFR 54 -----MVTMKNVLPLILCSWISAIHALKVSTCRYSE-KAIYEYPVTKLDGSP-FTLSSIQ 53

GKHVLVVNVATYUGLTF-QYVELNALHEELRHLGFTILGFPCDQFGKQEPGENNEILSAL 117 --MKPLGLTLLGFPCNQFGKQEPGTNHEILPGL 31 GKYILFVNVATYUGLTM-OYOELNALOEELKNNNFVILGFPSNOFGMOEPGRNDEILLGL 119 GKYLLFVNVATFUGLTM-QYQEMNALHEELKSNDFVILGFPCNQFGLQEPGRNDEIPLGL 119 GKYILFVNVASYUGLTG-QYLELNALQEELAPFGLVILGFPCNQFGKQEPGENSEILPSL 119 GKYVLFVNVASYUGLTG-QYIELNALQEELAPFGLVILGFPCNQFGKQEPGENSEILPTL 119 GKYVLFVNVASYUGLTG-QYVELNALQEEFEPFGLVILGFPCNQFGKQEPGDNSEILSTL 119 GKHVLFVNVATYUGLTA-QYPELNALQEELKPFGVVVLGFPCNQFGKQEPAKNSEILMGL 119 GKHVLFVNVATYUGLTA-QYPELNALQEELKPFGVVVLGFPCNQFGKQEPAKNSEILLGL 119 GKHVLFINVATYUGLTA-QYPELNALQEELKPFGVVLLGFPCNQFGKQEPGKNSEILSGL 119 GKHVLFVNVAAYUGLAA-QYPELNALQEELKNFGVIVLAFPCNQFGKQEPGTNSEILLGL 119 GKHVLFVNVATYUGLAA-QYPELNALQEELKNFGVIVLAFPCNQFGKQEPGTNSEILLGL 119 GKHVLFVNVATYCGLTI-OYPELNALQEDLKPFGLVILGFPCNOFGKQEPGDNLEILPGL 119 GKHVLFVNVATYCGLTA-QYPELNALQEELKPFGLVVLGFPCNOFGNQEPGENSEILPGL 11 GKHVLFVNVATYCGLTA-QYPELNALQEELKPFGLVVLGFPCNQFGNQEPGENSEILPGL 117
GKMVLFVNVATYUGLTL-QYLELNALQNELGPYGLVVLGFPSNQFGKQEPGQNSEILPAL 117 GKMVLFVNVATYUGLTL-QYLELNALQNELGPYGLVVLGFPSNQFGKQEPGQNSEILPAL 117 NEVTLLINVATYUGLTVAQYTGLNALLTHFNGRNFSVLAFPCDQFHLEEPGEDSEILNGL 108 GNVSMVINVATYUGATVPQYKAMNALSEEYTQSSFVTLAFPCNQFGLQQPEANDEILNGV 114 DKVAVI INTACFUGETWTQLPGMNALLQKYSKQGVVASGFPCDQFELQEPGLPREILPCY 113

$$
\text { ** : :* }::^{\star} \quad: \text { * }
$$

KYVRPGNGFVPN--FQLFEKGDVNGDGEQALFTFLKNACPPVGESFGATSNRLFWEPLKV 175 KHVRPGNGFVPN--FLLFEKGDVNGKDEOEVFTFLKNSCPPVGDVLGNPT-RMFWDPVKL 88 EYVRPGGKFVPN--FQLFEKGDINGRKEQKFYTFLKNSCPPVGDNFGSATNRLMWEPIKV 177 RYVRPGGNFIPN--FQLFEKGDVNGRKEQKFYTFLKNSCPPVGDTFGNPAFRLNWEPLRV 177 KYVRPGGGFVPN--FQLFEKGDVNGEKEQKFYTFLKNSCPPTSELLGSPG-RLFWEPMKV 176 KYVRPGGGFVPN--FQLFEKGDVNGEKEQKFYTFLKNSCPPTSELLGTSD-RLFWEPMKV 176 RYVRPGGGFIPN--FOLFEKGDVNGEKEOKFYTFLKNACPPTSELLGSPS-RLFWEPMKV 176 KYVRPGGGFVPN--FQLFEKGDVNGEKEQKVFTFLKNACPPTSDLLGSSS-QLFWEPMKV 176 KYVRPGGGFVPN--FQLFEKGDVNGEKEQKVFTFLKNSCPPTSDLLGSSN-QLFWEPMKV 176 KYVRPGGGFVPN--FQLFEKGDVNGEKEQKVFTFLKNSCPPTSDLLGSPK-QLFWEPMKV 176 KYVCPGSGFVPS--FQLFEKGDVNGEKEQKVFTFLKNSCPPTSDLLGSSS-QLFWEPMKV 176 KYVCPGSGFVPS--FOLFEKGDVNGEKEOKVFTFLKNSCPPTSDLLGSSS-OLFWEPMKV 176 KYVRPGKGFLPN--FQLFAKGDVNGENEQKIFTFLKRSCPHPSETVVMSK-HTFWEPIKV 176 KYVRPGGGYVPN--FQLFKKGDVNGETEQKVFTFLKQSCPHPS-----------WEPIMV 164 KYVRPGGGFVPN--FQLFQKGDVNGAKEQKVYSFLKNSCPPVAEEFGNPK-NLFWEPLRN 174 KHVNPGNGYVPN--FPMFQKADCNGVNEQAFYTYMKSCCPAISDVFISKI-RLYWDPIKN 91 MYVRPGNGYVPH PKLNI FGKI KVNGRHEHT IYKNVKASCPPTTLNLGSTR-NMYWNPVKS 167 MYVRPGHGFVPNKKIYFFSKTQVNGGSEDPLFTSIKASCPPTTNNIGITS-ELYWTPIKA 173 KYVRPGKGWIPHPNFHF LNKTKVNGKDENSLYAHLKSVCPQVTDEIGTRS-EMYWDPVKV 172

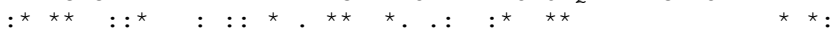

NDIKWNFEKFLLDPDGRPVMRWFPRVNVSEVRADILKYFHQLLQTAQ------------ 222

SDIKWNFEKFLVGPDGKPVMRWHPSVNISVVQADIRKYLLQLYTQQIFN----------- 137

NDVKWNFEKFLVGPDGRPVKRWLPRT PVAQVRREIMSYMKLQPGTQRLLMLGLEQK---- 233 NDI KWNFEKFLVGPDGRAVKRWHPRTSVAQVRREIVSYIKLQQGTQRLLMLGLEQK---- 233 HDIRWNFEKFLVGPDGI PIMRWYHRTTVSTVKMDI LAYMRRQAALAIKGK---------- 226 HDIRWNFEKFLVGPDGI PIMRWHHRTTVSNVKMDI LSYMRRQAALGVKRK---------- 226 HDIRWNFEKFLVGPDGVPVMRWYHRTTINTVKLDILAYMRRRAALEAKRO--------- 226

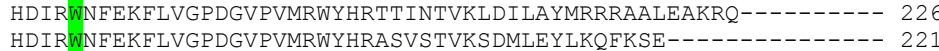
HDIRWNFEKFLVGPDGVPVMRWYHRASVSTVKSDIMEYLKQFKSE-------------- 221 HDIRWNFEKFLVGPDGVPVMRWFHRASVSTVKSDILEYLKOFTPE--_-_-_-_-_--- 221 HDIRWNFEKFLVGPDGVPVMHWFHOAPVSTVKSDILEYLKQFNTH-_-_-_-_-_-_-- 221

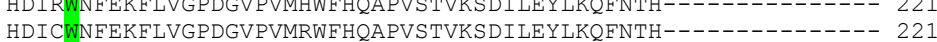

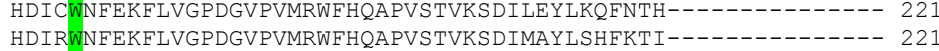

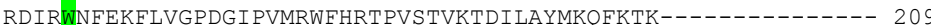
HDIKWNFEKFLVGTDGVPVMRWYHRANIATVKNDI IAYMRQQRGQ--_-_-_-_-_---- 219 TDIRWNFEKFLVDPAGKAVKRFSSYVTPGDLETVIDDFIKNWNDTSRDDTSGARSSRNSG 151 $\begin{array}{ll}\text { TDIRWNFEKFLVDPAGKAVKRFSSYVTPGDLETVIDDFIKNWNDTSRDDTSGARSSRNSG } & 151 \\ \text { TDITWNFNKFLLDKNGVPRYRISSDASPTSLIPYITTMLSE-------------- } 208\end{array}$

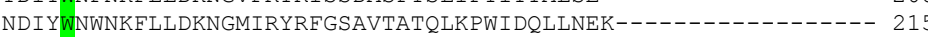
SDITWNYEKFLIDRKGKPRYRFGPSVLPSEIEPYIDSIL------------------- 211

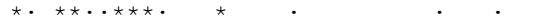


Danio rerio_GPX3

Perca flavescens GPX3

Xenopus tropicalis GPX3

Xenopus laevis_GPX $\overline{3}$

Canis Iupus_GPX3

Pongo abelii_GPX3

Sus scrofa_GPX3

Bos taurus_GPX6

Sus scrofa_GPX6

Equus cabalilus_GPX 6

Homo sapiens GPX6

Pan troglodytes GPx 6

Mus musculus_GPX5

Bos taurus_GP $\times 5$

Gallus gallus_GPX3

Branchiostoma floridae GPX

Ciona intestinalis GPX b

Ciona intestinalis_GPX $C$

Botryllus schlosseri_GPX3

(1) 
E: Amino acid alignment of $\mathrm{Cu} / \mathrm{Zn}$ SOD sequences obtained by CLUSTAL W. Fuxia highlight amino acids which coordinate copper in the catalytic sites and light blue highlight ion zinc. Green show histidine that bind copper and zinc and gray are the amino acid involved in antioxidant activity.

Ovis aries

Capra hircus

Bos taurus

Bos grunniens

Cervus elaphus

Callithrix jacchus

Macaca mulatta

Hylobates lar

Cavia porcellus

Equus caballus

Gallus gallus

Melopsittacus undulatus

Caretta caretta

Rana catesbeiana

Bufo gargarizans

Xenopus tropicalis

Xenopus laevis

Wuchereria bancrofti

Brugia malayi

Loa loa

Ascaris suum

Trichinella pseudospiralis

Branchiostoma floridae

Botryllus schlosseri

Caenorhabditis briggsae

Caenorhabditis remanei

Caenorhabditis elegans

Dictyocaulus viviparus

Ovis aries

Capra hircus

Bos taurus

Bos grunniens

Cervus elaphus

Callithrix jacchus

Macaca mulatta

Hylobates lar

Cavia porcellus

Equus caballus

Gallus gallus

Melopsittacus undulatus

Caretta caretta

Rana catesbeiana

Bufo gargarizans

Xenopus tropicalis

Xenopus laevis

Wuchereria bancrofti

Brugia malayi

Loa loa

Ascaris suum

Trichinella pseudospiralis

Branchiostoma floridae

Botryllus schlosseri

Caenorhabditis briggsae

Caenorhabditis remanei

Caenorhabditis elegans

Dictyocaulus viviparus

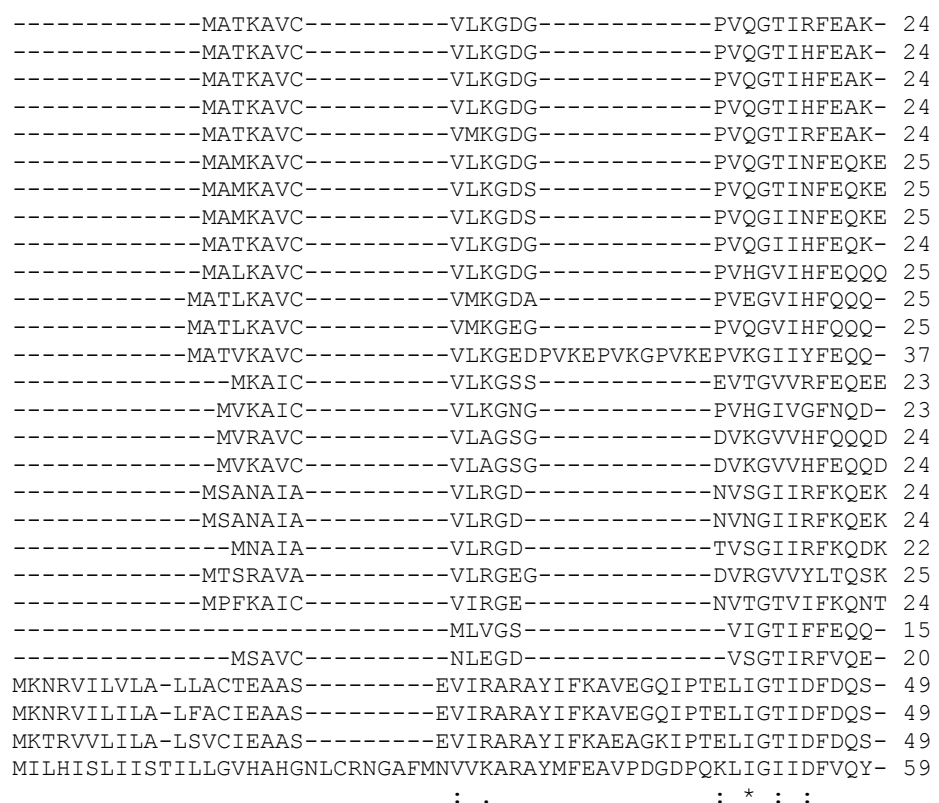

-GDKVVVTGSITGLTEGDHGF -GDKVVVTGSITGLTEGDHGF -GDTVVVTGSITGLTEGDHGF -GDTVVVTGSITGLTEGDHGE

-GNTVVVTGSITGLTEGDHGE SNGPVKVWGS ITGLAEGLHGF SNGPVKVWGSITGLTEGLHGE SNGPVKVYGRITGLTEGLHGE ANGPVVVKGRITGLVEGKHGE EGGPVVLKGFIEGLTKGDHGE GSGPVKVTGKITGLSDGDHGF GNGPVKVTGKISGLADGDHGE GNGPVTLSGSITGLTEGKHG -DGPVTVTGQITGLTDGKHGE -GGEVTVKGT INGLTDGLHGE -EGPVTVEGKIYGLTDGKHGF -EGAVSVEGKIEGLTDGLHGE EGLPTTISGEIKGLTPGLHGE EGSPTTISGEIKGLTPGLHGE ESSPTAINGEIKGLTPGLHGF EDEPTILKGEISGLTPGLHGF DTITGEIKGLT ----ACFREVTGLTEGPHG -GTDCVITGTVQGLTPGNHGE -GSFLKLNGSVSGLAAGKHGE -GSFLKLNGTVSGLQAGKHGF -GSFLKLNGSVSGLAAGKHGF I HEKGDTGNGCLSAGGHYNPHKLSHGAPDDSNRHIGDL 10
-RSLVKLNGTVSGLKSGLHGFHVHEKGNLANGCLAAGGHYNPYKLMHGAPSDSNRHVGDL 11

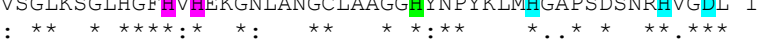


Ovis aries

Capra hircus

Bos taurus

Bos grunniens

Cervus elaphus

Callithrix jacchus

Macaca mulatta

Hylobates lar

Cavia porcellus

Equus caballus

Gallus gallus

Melopsittacus undulatus

Caretta caretta

Rana catesbeiana

Bufo gargarizans

Xenopus tropicalis

Xenopus laevis

Wuchereria bancrofti

Brugia malayi

Loa loa

Ascaris suum

Trichinella pseudospiralis

Branchiostoma floridae

Botryllus schlosseri

Caenorhabditis briggsae

Caenorhabditis remanei

Caenorhabditis elegans

Dictyocaulus viviparus

Ovis aries

Capra hircus

Bos taurus

Bos grunniens

Cervus elaphus

Callithrix jacchus

Macaca mulatta

Hylobates lar

Cavia porcellus

Equus caballus

Gallus gallus

Melopsittacus undulatus

Caretta caretta

Rana catesbeiana

Bufo gargarizans

Xenopus tropicalis

Xenopus laevis

Wuchereria bancrofti

Brugia malayi

Loa loa

Ascaris suum

Trichinella pseudospiralis

Branchiostoma floridae

Botryllus schlosseri

Caenorhabditis briggsae

Caenorhabditis remanei

Caenorhabditis elegans

Dictyocaulus viviparus
GNVKADKNGVAIVDIVDPLISLSGEYSIIGRTMVVHERPDDLGRG-GN--EESTKTGNAG 140 GNVKADKNGVAIVDIVDPLISLSGEYSI IGRTMVVHEKPDDLGRG-GN--EESTKTGNAG 140 GNVTADKNGVAIVDIVDPLISLSGEYSIIGRTMVVHEKPDDLGRG-GN--EESTKTGNAG 140 GNVTADKNGVAVVDIVDSLISLSGEYSIIGRTMVVHEKPDDLGRG-GN--EESTKTGNAG 140 GNVTADKNGVAKVDIVDSLISLSGEHSIIGRTMVVHEKPDDLGRG-GN--EESTKTGNAR 140 GNVTAGKDGVAKVSIEDSVISLSGDHSI IGRTLVVHEKADDLGKG-GN--EESKKTGNAG 142 GNVTAGKDGVAKVSFEDSVISLSGDHSIIGRTLVVHEKADDLGKG-GN--EESKKTGNAG 142 GNVTADKDGVAKVSIEDSVISLSGDHS I IGRTLVVHEKADDLGKG-GN--EESTKTGNAG 142 GNVTAGADGVANVSIEDSLISLSGANS I IGRTMVVHEKPDDLGKG-GN--EESTKTGNAG 141 GNVTADENGKADVDMKDSVISLSGKHSI IGRTMVVHEKQDDLGKG-GN--EESTKTGNAG 142 GNVTA-KGGVAEVEIEDSVISLTGPHCI IGRTMVVHAKSDDLGRG-GD--NESKLTGNAG 14 GNVTA-KGGVAEVAIEDSIISLSGPHSIVGRTMVVHEKCDDLGRG-GD--NESKLTGNAG 141 GNVIANKEGVAEVCIKDSLISLTGSQSI IGRTMVVHEKEDDLGKG-GN--DESLKTGNAG 154 GNVTS-AGGVADINIKDKLISLKGEHSI IGRTAVVHEKEDDLGKG-GD--NESLITGNAG 138 GNITS-KDGVAEFEFKDKIISLEGEHNI IGRTAVVHEKADDLGKG-GD--NESKVTGNAG 138 GNVTA-KDGVAEFKLTDSLISLKGNHS I IGRCAVVHEKEDDLGKG-GN--DESLKTGNAG 139 GNVTA-EGGVAQFKITDSLISLKGPNSIIGRTAVVHEKADDLGKG-GN--DESLKTGNAG 139 GNIVAEGDGTAHINISDKHVQLLGPNSIIGRS IVVHADQDDLGKGVGDKKDESLKTGNAG 144 GNIVAGADGTAH I DI SDKHVQLLGPNS I I GRS IVVHADQDDLGKGVGDKKDESLKTGNAG 144 GNIVAGADGTAH I DMS DKHVQLSGPNS I I GRS IVVHADQDDLGKGTGDKKDESLKTGNAG 142 GNVEADANGIAKFQIVDKLVQLHGKYSVIGRSMVVHVGEDDLGKGTGDKKEESLKTGNAG 145 GNIVAGSDGVAKIDIVDDOIKLTGEHSIIGRTMVVHIOEDDLGKG-GD--DESLKTGNAG 141 GNIVADASGTASVDITDNHLSLVGENSIIGRGVVVHADEDDLGKG-GH--ELSDTTGNSG 127 GNITADANGKAEVNITDKLVTLHGEYSVIGRAVVVHAGEDDLGLG-GF--PDSKTTGHAG 136 GNIESPASGDTAISVSDS LASLSGQYS I IGRSVVI HEKTDDLGRGNSD---QSKTTGNAG 165 GNIESPTSGDTAISVSDSLASLSGQYSIIGRSVVIHEKTDDLGRGNSD---OSKTTGNAG 165 GNIESPASGDTLISVSDSLASLSGQYSIIGRSVVIHEKTDDLGRGTSD---QSKTTGNAG 165 GNIVTSANGETVISISDPVITLNGYHSVIGRAVVI HADADDLGLGRSE---MSKSTGNSG 175

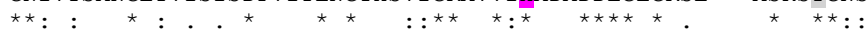

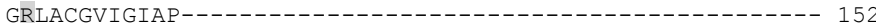

SCLACGVIGIAP---_-

SRLACGVIGIAP--

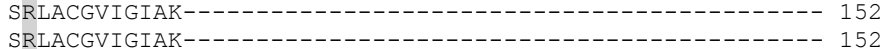

NRLACGVIGIAQ_-_-_-_-_-_-_-_-_-_-_-_-_-_-_-_-_-_-_-_- 152

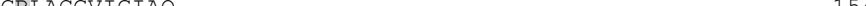

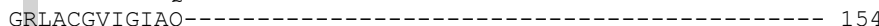

SRLACGVIGIAQ--_-_-_-_-_-_-_-_-_-_-_-_-_-_-_-_-_--- 154

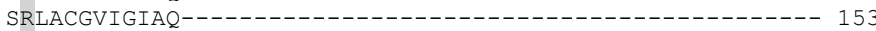

SRLACGVIGIAP-_-_-_-_-_-_-_-_-_-_-_-_-_-_-_-_-_-_-_-_-_-- 154

PRLACGVIGIAKC--_-_-_-_-_-_-_-_-_-_-_-_-_-_-_-_-_-_-_- 154

PRLACGVIGIAKS-_-_-_-_-_-_-_-_-_-_-_-_-_-_-_-_-_-_- 154

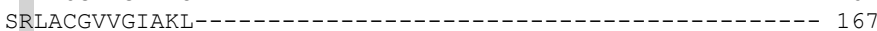

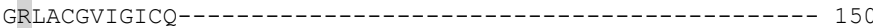

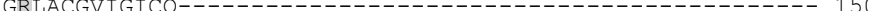

GRLACGVIGLCQ-_-_-_-_-_-_-_-_-_-_-_-_-_-_-_-_-_-_-_-_ 151

GRLACGVIGYSP-_-_-_-_-_-_-_-_-_-_-_-_-_-_-_-_-_-_ 151

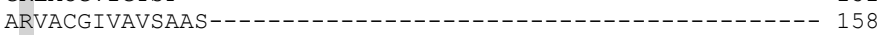

ARVACGIVAIGAAS--_-_-_-_-_-_-_-_-_-_-_-_-_-_-_-_--- 158

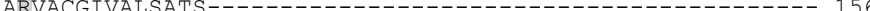

ARAACGVIAVAAPCEH-_-_-_-_-_-_-_-_-_-_-_-_-_-_-_-_-_-- 161

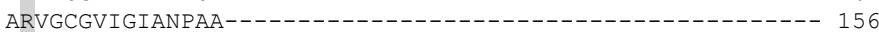

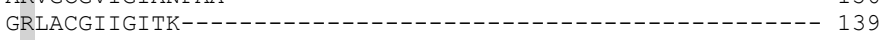

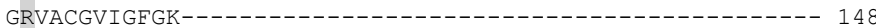

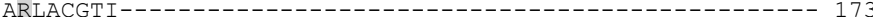

ARLACGTIGKY-_-_-_-_-_-_-_-_-_-_-_-_-_-_-_-_-_-_-_-_ 176

SRLACGTIGIVEERILETTTASLPPVTQSQPIGSSSYYYSTFYLPIILYFLLSRIL 221

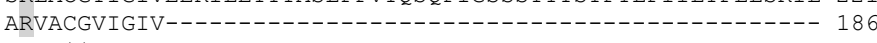

$$
{ }^{\star *}:
$$




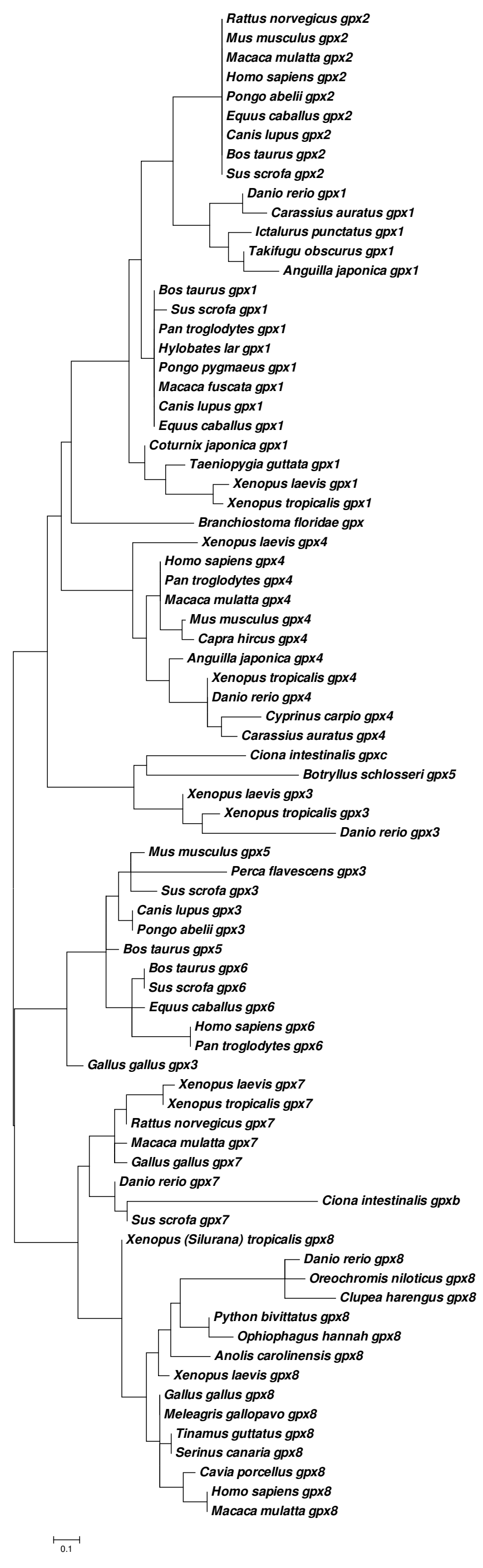


Figure S2. Evolutionary relationships (ML) among metazoan superoxide dismutases (SODs). Similar topologies were obtained with neighbor-joining (NJ), minimum evolution (ME), and unweighted pair group with arithmetic mean (UPGMA). 


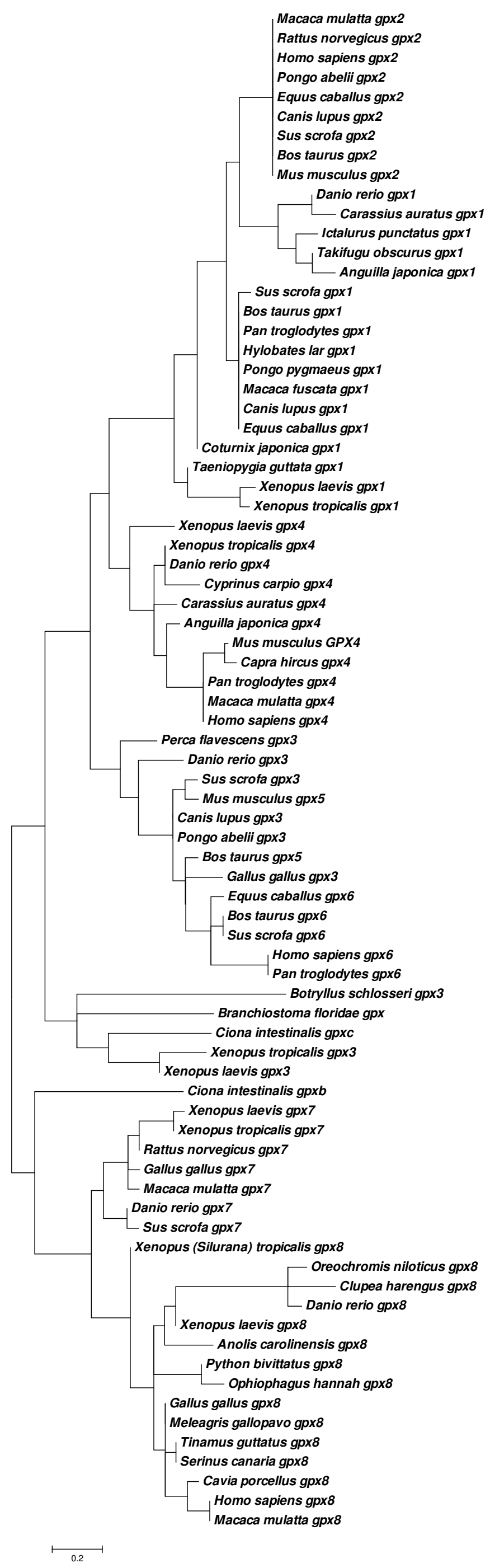


Figure S3. Evolutionary relationships (maximum likelihood; ML) among deuterostome glutathione peroxidases (GPxs). Similar topologies were obtained with neighbor-joining (NJ), minimum evolution (ME), and unweighted pair group with arithmetic mean (UPGMA). 
Supplementary Table 1: Sequences, available in GenBank, used for phylogeny.

\begin{tabular}{|c|c|c|}
\hline & GenBank ID & Species \\
\hline \multirow[t]{15}{*}{ GCLM } & NP 059001.1 & Rattus norvegicus \\
\hline & NP_032155.1 & Mus musculus \\
\hline & NP_001033232.1 & Bos Taurus \\
\hline & NP_002052.1 & Homo sapiens \\
\hline & NP_001007954.1 & Gallus gallus \\
\hline & NP_001080413.1 & Xenopus laevis \\
\hline & NP_001016536.1 & Xenopus tropicalis \\
\hline & ACO52032.1 & Rana catesbeiana \\
\hline & NP_956139.1 & Danio rerio \\
\hline & NP_001167414.1 & Salmo salar \\
\hline & AAQ96653.1 & Branchiostoma belcheri \\
\hline & XP_002128824.1 & Ciona intestinalis \\
\hline & ERG80734.1 & Ascaris suun \\
\hline & XP_001899959.1 & Brugia malayi \\
\hline & XP_003139745.1 & Loa loa \\
\hline \multirow[t]{13}{*}{ GS } & XP_002125323.1 & Ciona intestinalis \\
\hline & NP_001270338.1 & Macaca fascicularis \\
\hline & NP_000169.1 & Homo sapiens \\
\hline & XP_008993693.1 & Callithrix jacchus \\
\hline & NP_001081013.1 & Xenopus laevis \\
\hline & NP_001008045.1 & Xenopus tropicalis \\
\hline & NP_001006104.1 & Danio rerio \\
\hline & XP_006811195.1 & Branchiostoma floridae \\
\hline & NP_001015630.1 & Bos taurus \\
\hline & NP_037094.1 & Rattus norvegicus \\
\hline & ERG80184.1 & Ascaris suun \\
\hline & XP_001892534.1 & Brugia malayi \\
\hline & XP_003142623.1 & Loa loa \\
\hline \multicolumn{3}{|l|}{ GPxs } \\
\hline \multirow[t]{17}{*}{ Vertebrate GPx1 } & NP_001007282.2 & Danio rerio \\
\hline & AGC50802.1 & Carassius auratus \\
\hline & ACR20471.1 & Takifugu obscurus \\
\hline & ACN78878.1 & Anguilla japonica \\
\hline & XP_017306443.1 & Ictalurus punctatus \\
\hline & NP_001130041.1 & Taeniopygia guttata \\
\hline & BAF95575.1 & Coturnix japonica \\
\hline & NP_999366.1 & Sus scrofa \\
\hline & NP_776501.1 & Bos taurus \\
\hline & NP_001108591.1 & Canis lupus \\
\hline & NP_001159951.1 & Equus caballus \\
\hline & BAC67247.1 & Macaca fuscata \\
\hline & XP_003776297.2 & Pongo pygmaeus \\
\hline & NP_001070980.2 & Pan troglodytes \\
\hline & Q4ĀEI2.2 & Hylobates lar \\
\hline & NP_001088896.2 & Xenopus laevis \\
\hline & NP_001015740.2 & Xenopus tropicalis \\
\hline \multirow{3}{*}{ Vertebrate GPx2 } & NP_001156611.1 & Bos taurus \\
\hline & NP_001108608.1 & Sus scrofa \\
\hline & NP_001108607.1 & Canis lupus \\
\hline
\end{tabular}




\begin{tabular}{|c|c|c|}
\hline & NP_001108609.2 & Macaca mulatta \\
\hline & NP_001125093.3 & Pongo abelii \\
\hline & EAW80889.1 & Homo sapiens \\
\hline & NP_001159953.1 & Equus caballus \\
\hline & NP_899653.2 & Rattus norvegicus \\
\hline & NP_109602.2 & Mus musculus \\
\hline \multirow[t]{8}{*}{ Vertebrate GPx3 } & ACQ99329.1 & Perca flavescens \\
\hline & NP_001085319.2 & Xenopus laevis \\
\hline & NP_988961.2 & Xenopus tropicalis \\
\hline & NP_001131027.1 & Danio rerio \\
\hline & NP_001157926.1 & Canis lupus \\
\hline & NP_001124645.1 & Pongo abelii \\
\hline & NP_001108627.1 & Sus scrofa \\
\hline & NP_001156704.1 & Gallus gallus \\
\hline \multirow[t]{11}{*}{ Vertebrate GPx4 } & NP_001112361.1 & Macaca mulatta \\
\hline & AAH46163.1 & Homo sapiens \\
\hline & NP_001272641.1 & Capra hircus \\
\hline & NP_032188.3 & Mus musculus \\
\hline & NP_001139295.1 & Pan troglodytes \\
\hline & NP_001165215.2 & Xenopus laevis \\
\hline & ACN78879.1 & Anguilla japonica \\
\hline & ABO36294.1 & Carassius auratus \\
\hline & ACR33821.1 & Cyprinus carpio \\
\hline & NP_001291701.1 & Xenopus tropicalis \\
\hline & ABW76146.1 & Danio rerio \\
\hline \multirow[t]{2}{*}{ Vertebrate GPx5 } & AAI00750.1 & Mus musculus \\
\hline & NP_001020506.2 & Bos taurus \\
\hline \multirow[t]{5}{*}{ Vertebrate GPx6 } & AAY68223.1 & Homo sapiens \\
\hline & NP_001139297.1 & Pan troglodytes \\
\hline & NP_001131079.1 & Sus scrofa \\
\hline & NP_001156614.1 & Bos taurus \\
\hline & NP_001159955.1 & Equus caballus \\
\hline \multirow[t]{7}{*}{ Vertebrate GPx7 } & NP_001088904.1 & Xenopus laevis \\
\hline & NP_001072404.1 & Xenopus tropicalis \\
\hline & NP_001156717.1 & Gallus gallus \\
\hline & NP_001018337.1 & Danio rerio \\
\hline & XP_013847458.1 & Sus scrofa \\
\hline & NP_001152840.1 & Macaca mulatta \\
\hline & NP_001100143.1 & Rattus norvegicus \\
\hline \multirow[t]{15}{*}{ Vertebrate GPx8 } & NP_001088474.1 & Xenopus laevis \\
\hline & XP_012811797.1 & Xenopus tropicalis \\
\hline & NP_956516.1 & Danio rerio \\
\hline & XP_003455356.1 & Oreochromis niloticus \\
\hline & XP_012671344.1 & Clupea harengus \\
\hline & XP_007421400.1 & Python bivittatus \\
\hline & ETE72807.1 & Ophiophagus hannah \\
\hline & XP_003216232.3 & Anolis carolinensis \\
\hline & XP_423834.1 & Gallus gallus \\
\hline & XP_010723716.1 & Meleagris gallopavo \\
\hline & XP_010225014.1 & Tinamus guttatus \\
\hline & XP_009094073.1 & Serinus canaria \\
\hline & XP_003470318.1 & Cavia porcellus \\
\hline & NP_001008398.2 & Homo sapiens \\
\hline & XP_001098032.1 & Macaca mulatta \\
\hline
\end{tabular}




\begin{tabular}{|c|c|c|}
\hline Invertebrate GPxs & XP_002587571.1 & Branchiostoma floridae \\
\hline & NP_001177268.1 & Ciona intestinalis \\
\hline & NP_001177274.1 & Ciona intestinalis \\
\hline \multirow[t]{23}{*}{ Cu/Zn SOD } & NP_001138657.1 & Ovis aries \\
\hline & NP_001272479.1 & Capra hircus \\
\hline & NP_777040.1 & Bos taurus \\
\hline & Q52RN5.3 & Bos grunniens \\
\hline & AAB88116.1 & Cervus elaphus \\
\hline & XP_003467296.1 & Cavia porcellus \\
\hline & Q8HXQ3.3 & Hylobates lar \\
\hline & XP_002761406.1 & Callithrix jacchus \\
\hline & NP_001027976.1 & Macaca mulatta \\
\hline & NP_001075295.1 & Equus caballus \\
\hline & AAB25456.1 & Caretta caretta \\
\hline & NP_990395.1 & Gallus gallus \\
\hline & NP_001268474.1 & Melopsittacus undulatus \\
\hline & ACO51906.1 & Rana catesbeiana \\
\hline & ABD75370.1 & Bufo gargarizans \\
\hline & NP_001016252.1 & Xenopus tropicalis \\
\hline & CAA34602.1 & Xenopus laevis \\
\hline & XP_002590336.1 & Branchiostoma floridae \\
\hline & KJH46452.1 & Dictyocaulus viviparus \\
\hline & NP_001255002.1 & Caenorhabditis elegans \\
\hline & XP_002632365.1 & Caenorhabditis briggsae \\
\hline & XP_003113480.1 & Caenorhabditis remanei \\
\hline & XP_002122526.1 & Ciona intestinalis \\
\hline
\end{tabular}




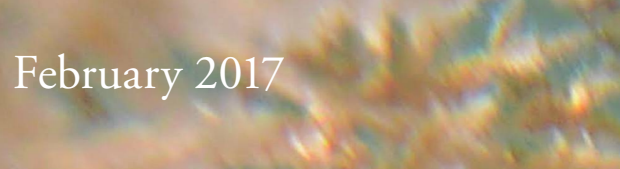

Volume 232 • Number 1
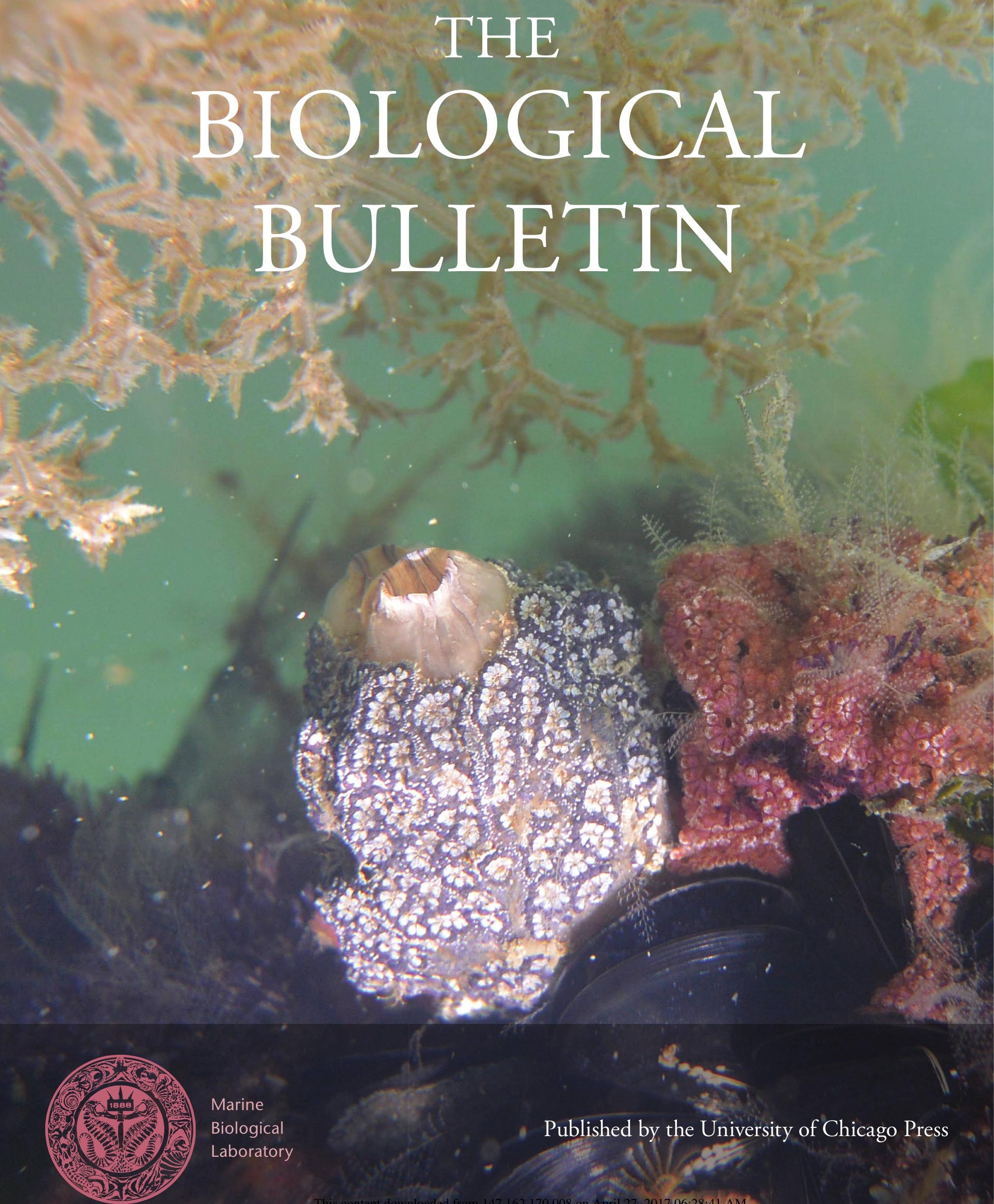


\section{Cover}

Pictured is a grouping of encrusting organisms in the Venetian Lagoon, an enclosed bay in the Adriatic Sea. In the center is a solitary ascidian (Styela plicata) growing over a bed of mussels (Mytilus galloprovincialis), its tunic almost completely covered by a colony of the compound ascidian Botryllus schlosseri. Another colony, differing in pigmentation, appears on the right. Colonies of hydrozoans (likely the genus Kirchenpaueria) are also visible. Botryllus schlosseri is one of the species that characterizes the climax of the ecological succession in the Venetian Lagoon, and it is widely used as a model organism for evolutionary studies ranging from reproduction to immune defense.

On pages $45-57$ of this issue of The Biological Bulletin, authors Franchi, Ballin, and Ballarin report the identification and characterization of transcripts for Cu/Zn superoxide dismutase (SOD), gamma glutamylcysteine ligase modulatory subunit (GCLM), glutathione synthase (GS), and two glutathione peroxidases (i.e., GPx3 and GPx5), all involved in protection from reactive oxygen species (ROS). The authors also studied the expression of antioxidant genes in the course of the blastogenetic cycle, assuring the cyclical generation change in Botryllus colonies. In addition, they investigated the effects of cadmium (Cd), an inducer of oxidative stress, on the transcription of the above-named genes.

Their results indicate that 1 ) gene transcription is modulated during the blastogenetic cycle and upon exposure to $\mathrm{Cd}$, and 2) hemocytes synthesize both enzymatic and nonenzymatic antioxidants, in line with the idea that they represent a major detoxification system for ascidians.

Credits: Photo, Euichi Hirose, Faculty of Science Department of Chemistry, Biology, and Marine Science, University of the Ryukyus, Okinawa, Japan. Cover design, Sarah Gardiner, University of Chicago 